Published in "ISPRS Journal of Photogrammetry and Remote Sensing 109: 178-192, 2015"

which should be cited to refer to this work.

\title{
Mapping slope movements in Alpine environments using TerraSAR-X interferometric methods
}

\author{
Chloé Barboux ${ }^{\mathrm{b}}$, Tazio Strozzi ${ }^{\mathrm{a}, *}$, Reynald Delaloye ${ }^{\mathrm{b}}$, Urs Wegmüller $^{\mathrm{a}}$, Claude Collet $^{\mathrm{b}}$ \\ ${ }^{a}$ Gamma Remote Sensing, Worbstrasse 225, 3073 Gümligen, Switzerland \\ ${ }^{\mathrm{b}}$ Department of Geosciences - Geography, University of Fribourg, Ch. du Musée 4, 1700 Fribourg, Switzerland
}

\begin{abstract}
Mapping slope movements in Alpine environments is an increasingly important task in the context of climate change and natural hazard management. We propose the detection, mapping and inventorying of slope movements using different interferometric methods based on TerraSAR-X satellite images. Differential SAR interferograms (DInSAR), Persistent Scatterer Interferometry (PSI), Short-Baseline Interferometry (SBAS) and a semi-automated texture image analysis are presented and compared in order to determine their contribution for the automatic detection and mapping of slope movements of various velocity rates encountered in Alpine environments. Investigations are conducted in a study region of about $6 \mathrm{~km} \times 6 \mathrm{~km}$ located in the Western Swiss Alps using a unique large data set of 140 DInSAR scenes computed from 51 summer TerraSAR-X (TSX) acquisitions from 2008 to 2012 . We found that PSI is able to precisely detect only points moving with velocities below $3.5 \mathrm{~cm} / \mathrm{yr}$ in the LOS, with a root mean squared error of about $0.58 \mathrm{~cm} / \mathrm{yr}$ compared to DGPS records. SBAS employed with 11 days summer interferograms increases the range of detectable movements to rates up to $35 \mathrm{~cm} / \mathrm{yr}$ in the LOS with a root mean squared error of $6.36 \mathrm{~cm} / \mathrm{yr}$, but inaccurate measurements due to phase unwrapping are already possible for velocity rates larger than $20 \mathrm{~cm} /$ year. With the semi-automated texture image analysis the rough estimation of the velocity rates over an outlined moving zone is accurate for rates of " $\mathrm{cm} / \mathrm{day}$ ", "dm/month" and " $\mathrm{cm} / \mathrm{month",} \mathrm{but} \mathrm{due} \mathrm{to} \mathrm{the} \mathrm{decorrelation} \mathrm{of} \mathrm{yearly} \mathrm{TSX} \mathrm{interferograms} \mathrm{this}$ method fails for the observation of slow movements in the "cm/yr" range.
\end{abstract}

\section{Introduction}

In the Swiss Alpine periglacial belt - defined as the sparsely vegetated portion of the mountain slope in between the tree line up to the top of the mountains excluding the glaciated areas (in between $\sim 2300 \mathrm{~m}$ and $\sim 3000 \mathrm{~m}$ a.s.l.) - various kinds of slope movement can be encountered with velocity rates varying from some millimeters to several meters per year. Many moving zones are related to the creep of frozen debris (rock glaciers, pushmoraines). Shallow to deep-seated landslides affecting frozen as well as unfrozen debris or rock are also likely to occur. In the context of climate change and natural hazard management in mountain, especially in densely inhabited Alpine regions, there is a great need to investigate methods to detect and map slope movements at regional scale (from an entire mountain slope to much larger areas).

\footnotetext{
* Corresponding author
}

An inventory of slope movements over the whole Swiss Alps was compiled in the past based on the visual interpretation of Differential SAR Interferograms (DInSAR) computed from image pairs of the ERS- $1 / 2$ and JERS- 1 sensors characterized by time intervals of 1 day up to 3 years (Delaloye et al., 2007; Barboux et al., 2014). For a study area of about $37 \mathrm{~km}^{2}$ over the westfacing slope of the Saas Valley in the Canton of Valais, 44 DInSAR polygons outlining moving zones with an almost homogeneous deformation rate were visually inventoried from images of the 1990s (Fig. 1). This study area is representative of the typical landscape encountered in the western Swiss Alps, namely high slopes, rugged terrain and altitude ranging from $1500 \mathrm{~m}$ a.s.l. at the valley bottom (western part of the studied area) up to about $4000 \mathrm{~m}$ a.s.l. at the top of the mountain (eastern part). The 44 moving zones inventoried in this restricted area are classified into signals from four different magnitude orders of velocity rate, namely the classes "cm/day", "dm/month", "cm/month" and "cm/year" (Delaloye et al., 2007) and are related to the typical Alpine landforms encountered in the periglacial Alpine belt described above. 


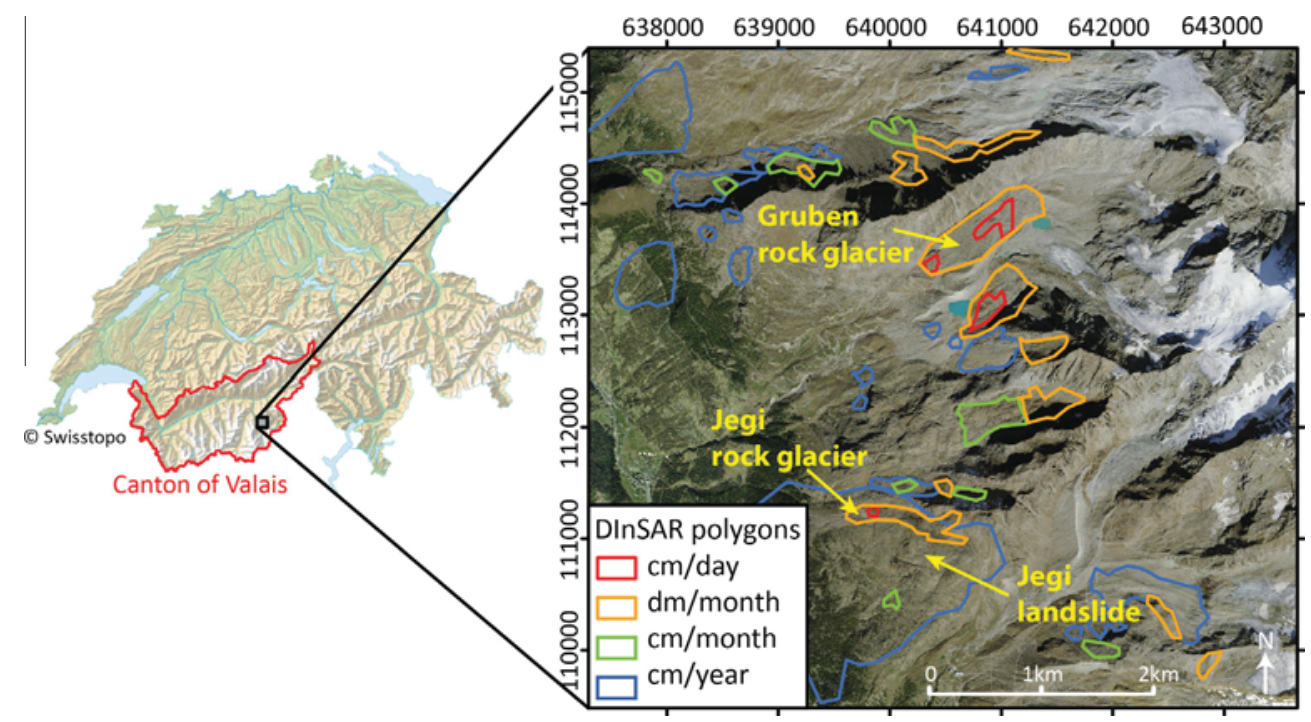

Fig. 1. Detected DInSAR polygons using ERS-1/2 and JERS-1 DInSAR data from the 1990s over the studied area (Delaloye et al., 2007). Image background is an orthoimage from 2010 @ Swisstopo. The Swiss coordinate system is used for all maps, units are in meters. Image size is $5.9 \times 6.3 \mathrm{~km}$, central coordinates are $46^{\circ} 0.5^{\prime} 45^{\prime \prime} \mathrm{N} / 7^{\circ} 57^{\prime} 45^{\prime \prime} \mathrm{E}$. The location of two rock glaciers (Jegi and Gruben) seasonally surveyed by DGPS campaigns is indicated.

Studies carried out in various parts of the Alps have shown the acceleration of rock glacier surface velocities and the destabilization of several landforms over the two last decades potentially related to the changing permafrost creep conditions in the Alps (Delaloye et al., 2010). Consequently, it is worthy to evaluate improved methods for an automatic update of existing slope movement inventories.

Since the compilation of the first inventory new SAR sensors, advanced processing techniques and Digital Elevation Models (DEM) to compensate for the topographic related phase have been available. ENVISAT ASAR (Fig. 2a) and ALOS PALSAR dualpolarization (Fig. 2b) data have similar spatial resolutions, acquisition time intervals and wavelengths of those of ERS- $1 / 2$ respectively JERS- 1 and provide therefore similar information of the one observed in Fig. 1 for a different time span. The availability of large historic data archives at C-band (ERS- $1 / 2$ and ENVISAT) also permitted the application of Persistent Scatterer Interferometry (PSI) to mitigate temporal and geometric decorrelation and inhomogeneities in the tropospheric path delay of DinSAR data (Ferretti et al., 2001; Wegmüller et al., 2003). The PSI sensitivity to ground motion is very high, which permits assessing even slow creeping at $\mathrm{mm} /$ year scale (Fig. 2c), but in mountainous regions only summer images can be considered and there is therefore an important data gap between November and June of every year. This is limiting the possibility to detect with ERS and ENVISAT PSI rates of movements larger than about $1-2 \mathrm{~cm} / \mathrm{yr}$. In recent years a significant further improvement was possible with the use of the new generation of satellite SAR sensors TerraSAR-X (Fig. 2d) and Cosmo-Skymed characterized by a higher spatial resolution and a shorter revisiting time (Notti et al., 2010; Herrera et al., 2010; Bovenga et al., 2012). In addition, the availability in Switzerland of a very high resolution DEM (SwissALTI3D (C) Swisstopo) with a spatial resolution of $2 \mathrm{~m}$ and an accuracy of all three dimension reaching $1-3 \mathrm{~m}$ in alpine terrain allows to compute X-band differential interferograms even with perpendicular baselines larger than $500 \mathrm{~m}$ without any noticeable artifacts.

The availability of a unique large data set of TerraSAR-X summer acquisitions from 2008 to 2012, the occurrence of both well-defined isolated landforms and complex systems with superimposed moving landforms, and the relative dryness of the study area with a long and continuous snow-free period makes the Saas
Valley a region particularly suitable to test the performance of advanced SAR processing methods as Short Baseline Interferometry (SBAS; Berardino et al., 2002; Lanari et al., 2004), Interferometric Point Target Analysis (IPTA; Werner et al., 2003; Wegmuller et al., 2004) and texture analysis of interferometric phase images (Barboux, 2014) for the detection, mapping and inventorying of slope movements. The development of alternative methods would in particular support experts in the inventorying procedure by allowing a reduction of the working time and of the subjectivity of the DInSAR signal interpretation of each differential SAR interferogram. The performance of the proposed methods for mapping various slope movements with different size and velocity encountered in Alpine terrain will be intercompared and validated with differential GPS data.

\section{Data and methods}

\subsection{TerraSAR-X data and Differential SAR Interferometry (DInSAR)}

A large set of TerraSAR-X data was acquired in descending mode over the eastern part of the Canton of Valais. Up to 2012, a total of 51 images are available for the months of May to October of 2008 (4), 2009 (13), 2010 (7), 2011 (12) and 2012 (15). TerraSAR-X data were acquired in Stripmap mode at HH polarization with a nominal spatial resolution of $3 \mathrm{~m}$ and an incidence angle of $45^{\circ}$ to reduce problems of layover. In Differential Synthetic Aperture Radar Interferometry (DInSAR), displacement is derived from the measurement of the phase difference of the signals acquired by two satellite SAR acquisitions after compensation of the topographic effects with use of an external DEM (Bamler and Hartl, 1998; Rosen et al., 2000). Major advantages of this technique are the wide area coverage (hundreds of $\mathrm{km}^{2}$ ), the high sensitivity to surface displacement (centimeters to millimeters), and the availability since 1991 of a large archive of satellite acquisitions with repeat-cycles on the order of one month. Despite limitations due to vegetation cover, the special SAR viewing geometry, atmospheric artifacts, and snow cover, short-baseline interferograms are successfully applied in mountainous areas for the mapping and monitoring of rock glaciers and landslides (Barboux et al., 2012, 2014; Delaloye et al., 2007; García-Davalillo et al., 2014; Lambiel et al., 2008; Strozzi et al., 2004, 2005, 2010). 


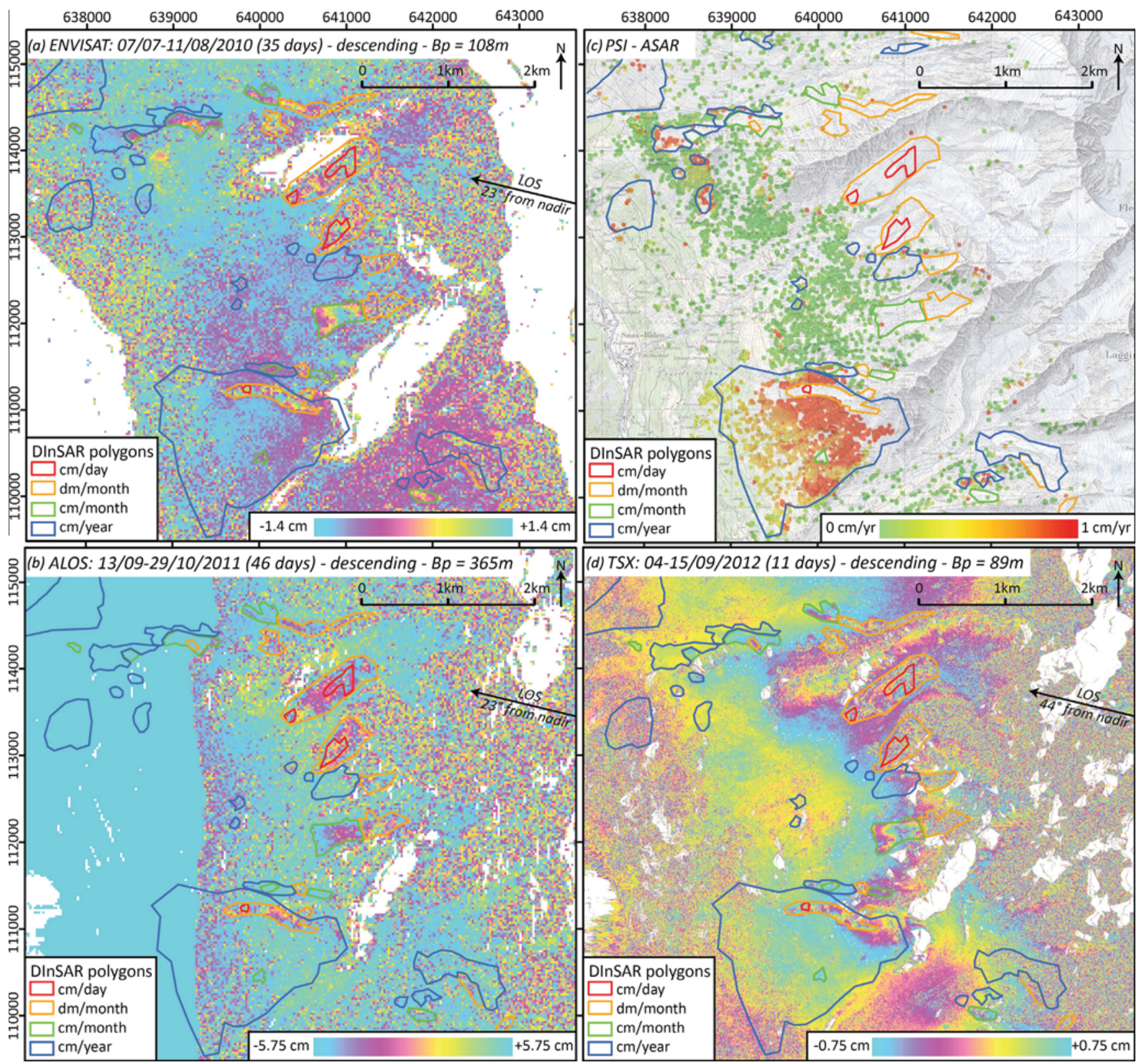

Fig. 2. (a) SAR interferogram and (b) the related PSI signal using Envisat sensor and additional examples of (c) ALOS and (d) TSX SAR interferograms observed on the study area. The polygons are those of Fig. 1 mapped manually using ERS-1/2 and JERS-1 DInSAR data.

We computed with the GAMMA commercial InSAR processing software a total of 140 interferometric phase and coherence images with baselines shorter than $250 \mathrm{~m}$ at $5 \mathrm{~m}$ posting (Table 1 ). Differential SAR interferograms were processed in the two-pass approach using the SwissAlti3D DEM oversampled to $5 \mathrm{~m}$ (2011 (c) Swisstopo). SwissAlti3D DEM has an estimated vertical accuracy of 1-3 $\mathrm{m}$ for an original $2 \mathrm{~m}$ pixel spacing and is based on airborne laser scanning for heights up to $2000 \mathrm{~m}$ and on stereocorrelation of airborne images acquired from 2008 to 2011 for areas above $2000 \mathrm{~m}$. Standard processing steps included co-registration of the TerraSAR-X acquisitions, multi-looked interferogram generation using a $5 \times 5$ window, estimation and removal of the topographic phase using the DEM, baseline refinement and subtraction of a height-dependent atmospheric phase contribution. For the estimation of the coherence images used in the texture image analysis, an adaptive filtering function based on local fringe spectrum (Goldstein and Werner, 1998) was applied to reduce noise in the phase images. The function computes locally the interferogram
Table 1

Number of selected interferograms from summers 2008 to 2012.

\begin{tabular}{lc}
\hline Time intervals (day) & Number of pairs \\
\hline 11 & 11 \\
22 & 10 \\
33 & 10 \\
44 & 10 \\
55 & 10 \\
66 & 9 \\
77 & 12 \\
35 & 11 \\
363 & 12 \\
374 & 7 \\
638 & 8 \\
649 & 6 \\
660 & 5 \\
704 & 5 \\
Total & 6 \\
\hline
\end{tabular}


power spectrum, designs a filter based on the power spectrum, filters the interferogram, and estimates the phase noise coherence value for the filtered interferogram. According to software requirements, a small Fast Fourier Transform (FFT) of size of 32 was chosen for the filtering of rapidly changing phase associated with the topographic phase of rugged terrain.

\subsection{Persistent Scatterer Interferometry (PSI)}

The application of DInSAR is limited by temporal and geometric decorrelation and inhomogeneities in the tropospheric path delay. In Persistent Scatterer Interferometry (PSI) differential SAR Interferometry is applied only on selected pixels that do exhibit a point-target scattering behavior and are persistent over an extended observation time period (Ferretti et al., 2001; Wegmüller et al., 2003). Through the use of many SAR scenes, even if separated by large baselines, errors resulting from atmospheric artefacts are reduced and a higher accuracy can be achieved. Over built-up areas with numerous man-made structures or in regions where rocks or single infrastructures (e.g. houses, power line masts) scattered outside villages are visible, it is therefore possible to estimate the progressive deformation of the terrain at millimeter accuracy. In mountainous regions the number of persistent scatterers is limited by the sparse urbanization, the large forest cover, and areas of shadow and layover (Farina et al., 2006; Colesanti and Wasowski, 2006; Strozzi et al., 2006; Meisina et al., 2008).

In our PSI analysis (Wegmuller et al., 2004; Strozzi et al., 2009) the selection of candidate point targets is based on the temporal mean-to-standard deviation ratio of the co-registered TerraSAR-X intensity images and the spectral correlation averaged over the single look complex stack. Interferometric processing is performed with respect to the central reference image of September 11, 2009 with baseline values between $-166 \mathrm{~m}$ and $183 \mathrm{~m}$ (Table 2). SwissAlti3D DEM is considered for initial topographic related phase estimation and removal. Two-dimensional linear regression with respect to height and deformation rate is iterated various times in order to include as many points as possible, because the quality of potential additional points can be evaluated more reliably if the improved model for the validated points is available. At the last stage, points with a regression standard deviation of less than $1.0 \mathrm{rad}$ are considered. The discrimination of atmospheric phase, nonlinear deformation, and error terms is based on their differing spatial and temporal dependencies.

\subsection{Short Baseline Interferometry (SBAS)}

For mountainous regions one major limitation to the use of PSI is the presence of snowcover. Interferograms computed with images acquired from November to June of every year are mostly decorrelated. Also yearly TerraSAR-X interferograms are largely decorrelated, caused by the surface deformation of soils, large deformation of the ground and/or changes in the vegetation cover. Therefore, PSI results are mainly restricted to rates of movements of a few $\mathrm{cm} / \mathrm{yr}$. On the other hand, TerraSAR-X is able to provide consistent series of interferograms with 11 days time intervals, which show very good coherence under snow-free conditions and permits application of a Short-Baseline Interferometry (SBAS) processing approach (Berardino et al., 2002; Cascini et al., 2010; Lauknes et al., 2010). Based on the singular value decomposition inversion described by Lee et al. (2010) and Schmidt and Burgmann (2003), we formulate in our algorithm a set of linear equations that are functions of the deformation velocities during the time intervals spanned by the interferogram. DEM height correction is not applied because of the excellent quality of SwissAlti3D, which does not produce any noticeable artifacts also for X-band interferograms with spatial baseline as large as $500 \mathrm{~m}$.

The short-baseline (SBAS) processing sequence applied here includes the computation of a series of multi-look differential interferograms, the removal of the topographic-related phase with use of SwissAlti3D DEM, phase unwrapping, the removal of a linear atmospheric signal with respect to height, the computation of cumulative displacement maps and time series using Singular Value Decomposition (SVD), and terrain-corrected geocoding. The baseline distribution of interferograms is restricted within $-282 \mathrm{~m}$ to $331 \mathrm{~m}$. Phase unwrapping was performed only for pixels with coherence values larger than 0.4 computed on an adaptive window with size between 3.0 and 9.0. Adaptive filtering of the

Table 2

Spatial baseline and acquisition time of interferograms considered in PSI. The central reference image is September 11, 2009.

\begin{tabular}{|c|c|c|c|c|c|c|c|}
\hline \# & Date (yyyymmdd) & Spatial baseline (m) & Time interval (day) & $\#$ & Date (yyyymmdd) & Spatial baseline $(\mathrm{m})$ & Time interval (day) \\
\hline 1 & 20080811 & 183.2592 & -396 & 27 & 20110622 & 61.8237 & 649 \\
\hline 2 & 20080822 & -100.606 & -385 & 28 & 20110725 & -96.2326 & 682 \\
\hline 3 & 20080913 & -121.97 & -363 & 29 & 20110805 & -5.5401 & 693 \\
\hline 4 & 20080924 & -44.0022 & -352 & 30 & 20110816 & 172.711 & 704 \\
\hline 5 & 20090524 & 67.9389 & -110 & 31 & 20110827 & -51.3479 & 715 \\
\hline 6 & 20090604 & 92.9711 & -99 & 32 & 20110907 & -60.707 & 726 \\
\hline 7 & 20090626 & 3.605 & -77 & 33 & 20110918 & -165.866 & 737 \\
\hline 8 & 20090707 & -38.8573 & -66 & 34 & 20110929 & 94.2386 & 748 \\
\hline 9 & 20090718 & -32.3875 & -55 & 35 & 20111010 & -3.2289 & 759 \\
\hline 10 & 20090729 & -142.093 & -44 & 36 & 20111021 & 20.8579 & 770 \\
\hline 11 & 20090809 & 154.8672 & -33 & 37 & 20120528 & 47.6992 & 990 \\
\hline 12 & 20090831 & -124.304 & -11 & 38 & 20120608 & 8.9114 & 1001 \\
\hline 13 & 20090911 & 0 & 0 & 39 & 20120619 & 41.5318 & 1012 \\
\hline 14 & 20090922 & -2.5012 & 11 & 40 & 20120630 & 73.4568 & 1023 \\
\hline 15 & 20091003 & -98.882 & 22 & 41 & 20120711 & -166.634 & 1034 \\
\hline 16 & 20091014 & -79.3109 & 33 & 42 & 20120722 & 166.4561 & 1045 \\
\hline 17 & 20091025 & -161.073 & 44 & 43 & 20120802 & 81.4773 & 1056 \\
\hline 18 & 20100613 & 124.6117 & 275 & 44 & 20120813 & 49.0954 & 1067 \\
\hline 19 & 20100624 & 18.646 & 286 & 45 & 20120824 & -114.114 & 1078 \\
\hline 20 & 20100705 & -47.563 & 297 & 46 & 20120904 & -38.3144 & 1089 \\
\hline 21 & 20100716 & -109.788 & 308 & 47 & 20120915 & 50.9465 & 1100 \\
\hline 22 & 20100829 & 118.2335 & 352 & 48 & 20120926 & -74.0102 & 1111 \\
\hline 23 & 20100909 & 20.3591 & 363 & 49 & 20121007 & 150.9254 & 1122 \\
\hline 24 & 20100920 & -55.5414 & 374 & 50 & 20121018 & -39.7306 & 1133 \\
\hline 25 & 20110531 & 51.0003 & 627 & 51 & 20121029 & 132.557 & 1144 \\
\hline 26 & 20110611 & -54.8933 & 638 & & & & \\
\hline
\end{tabular}


interferograms before phase unwrapping is avoided because of the limited size of the observed geophysical phenomena. The design matrix is augmented with a set of additional weighted constraints on the acceleration that penalize rapid velocity variations. The weighting factor can be varied from 0 (no smoothing) to a large values $(>10)$ that yield an essentially linear time series solution. We set the weighting factor at 0.5 to take into account deformation non-linearity. Processing was performed independently for every year from 2008 to 2012. Here we focus on the 2012 results, because of the larger number of available TerraSAR-X acquisitions, leading to a more robust mean deformation rate map and a longer time series of displacements, and the possibility to validate the results with a larger set of coincident ground-truth. In addition, stacking of all 11 days InSAR data from 2008 to 2012 was performed to generate a mean displacement rate map. The 20082012 stacking result is very similar to the SBAS mean deformation map for 2012 alone and is therefore no more discussed here.

\subsection{Semi-automated texture analysis of interferometric phase image}

A method to semi-automatically detect slope movements from DinSAR data was developed on the basis of the visual signal interpretation used for the compilation of slope movement inventories performed in the Swiss Alps (Barboux, 2014). This method is considered to be an alternative to PSI and SBAS in the case of rapidly moving landforms (velocities larger than about $30 \mathrm{~cm} / \mathrm{yr}$ ), which are anticipated to cause phase unwrapping errors of interferograms. In addition, with this method the phase noise, which is by default excluded by phase unwrapping, is also considered as an important tool to identify the position, extent and contour of rapid displacements.
Our procedure is divided in three parts. The first step consists in the classification using different statistical methods of textural image features extracted every $25 \mathrm{~m}$ from the interferometric phase (Fig. 3a) according to three DInSAR signal patterns: (1) no change defined by a plain pattern, (2) smooth change characterized by a (partly) fringe pattern and (3) decorrelated signal expressed by a noisy pattern (Barboux et al., 2013). The texture is evaluated around the considered pixel within a radius of $40 \mathrm{~m}$ ( 8 pixels) related to the size of the landforms that have to be detected. For every interferogram the DInSAR signal map is finally produced at $5 \mathrm{~m}$ resolution by interpolation (Fig. 3b). In a second step, selected interferograms with the same time interval are combined in order to determine the overall slope movements at this specific time interval. This combination is performed in order to produce a map assessing the occurrence of each DInSAR signal class for the selected studied period and to prevent the presence of single artifacts due e.g. to atmosphere or snow. Thus, pixels are classified into the most represented DInSAR signal class in the set of selected interferograms. An extra class "NaN" is added indicating when the algorithm is not able to clearly classify the pixel. The classification can be finally transposed into the slope movement's index according to the three following classes: (1) plain pattern corresponding to "no deformation", (2) (partly) fringe pattern potentially related to "gentle deformation" and (3) noise pattern potentially related to "large deformation" (Fig. 3c). Exceptional variations in the velocity rate of a landform observed during one single interferogram will be also smoothed by this process and cannot be detected. However, noise related to vegetation or glaciated area, persistent over all interferograms, has to be interpreted correctly.

In the third part we propose to use the automatic mapping based on specific time intervals for the rough estimating of the

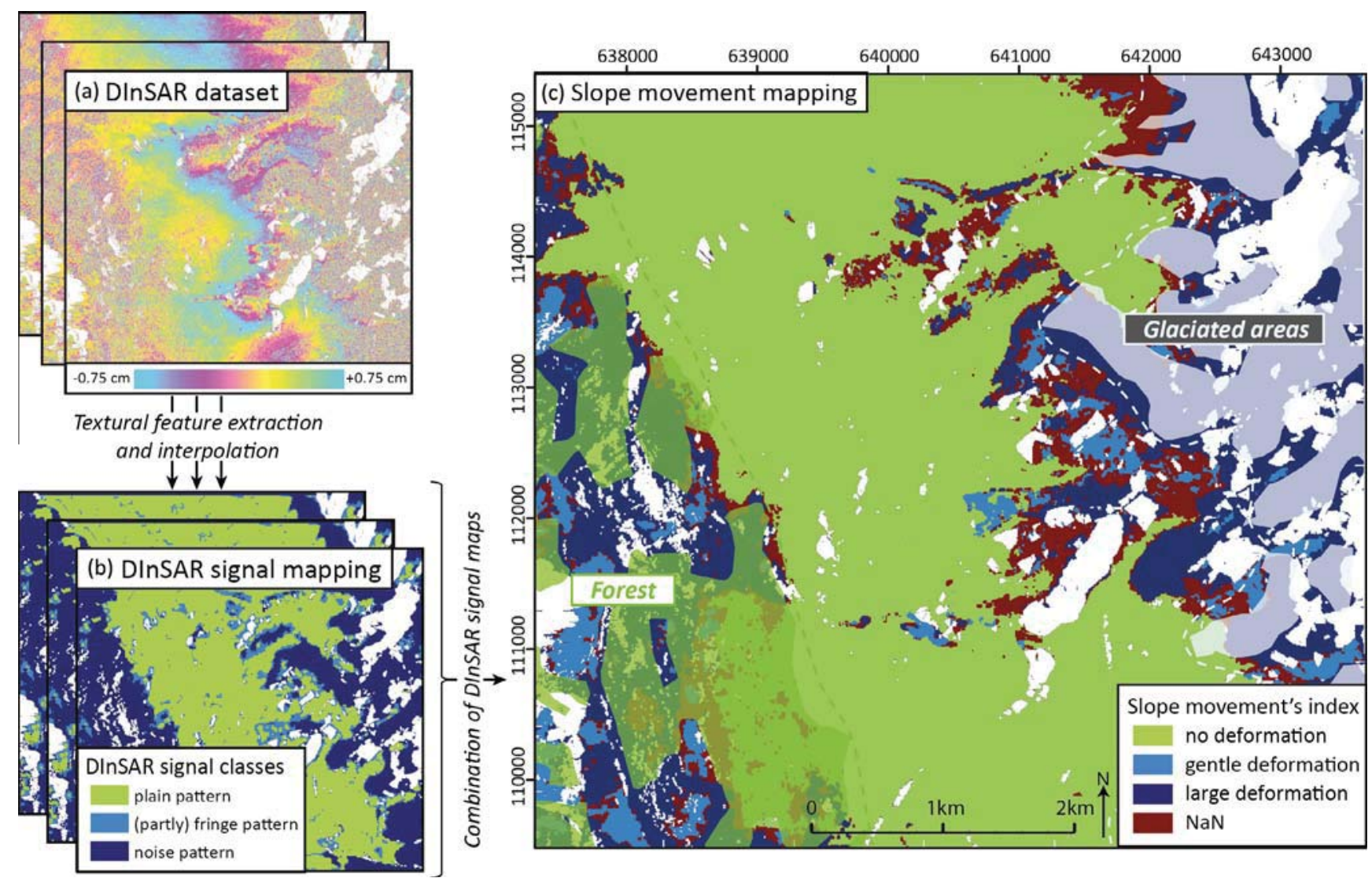

Fig. 3. Process of semi-automated DInSAR and slope movements mapping for a specific time interval. Layover and shadow in white. 
velocity rate of a landform (Fig. 4). The process requires several slope movement maps (Fig. 3c) derived from a large set of TSX DInSAR data with various time intervals. The time intervals are those of the available interferograms, i.e. multiple of 11 days up to 88 days within the snow-free season and three to five other intervals after one and two years during mid summer (Table 1 ). The estimation is performed over a spatially outlined area with an almost homogeneous deformation rate, for instance a DInSAR polygon of the available inventory. For every polygon the variation of the proportion of each slope movement's index given by the series of slope movement maps, indicated as "Deformation rate", is analyzed as a function of the time intervals (Fig. 4b). On the basis of the deformation rate two thresholds are selected: (1) s_stab corresponding to the time interval until the proportion of "no deformation" index is higher than $50 \%$ and (2) $s_{-}$dec corresponding to the time interval from when the proportion of "large deformation" index is higher than 50\% (Fig. 4b). The period in between these two thresholds represents the time intervals where (partly) fringe pattern possibly related to gentle deformation can be observed.

In Fig. 4 two examples are indicated. For the DInSAR polygon 863 a noise pattern related to large deformation is already classified for about $60 \%$ of the 11 days interferograms, meaning that the $s \_$dec index is 11 days and the s_stab index is not applicable. For the DInSAR polygon 862 no deformation is classified for a little bit more than $50 \%$ of the 11 days interferograms and a noise pattern related to large deformation is classified for more than $50 \%$ of the interferograms after 22 days. In this case the s_stab index is 11 days and $s_{-}$dec index 22 days. Table 3 is then used to evaluate the velocity rate according to the 4 classes used in previous slope movement inventories using DInSAR, namely the classes "cm/year", "cm/month", "dm/month" and "cm/day". According to Table 3 Polygon 863 is classified in the $\mathrm{cm} /$ day class (noise pattern even after 11 days), while polygon 862 is attributed to the $\mathrm{dm} / \mathrm{month}$ class (noise pattern even after 22 days).

\section{Results}

\subsection{Results of PSI and SBAS}

PSI results obtained from TerraSAR-X data from 2008 to 2012 are presented in Fig. 5a and show slow creeping or sliding with rates up to $4 \mathrm{~cm} / \mathrm{y}$. In particular, the Jegi landslide in the southwest of the study region is very well covered with valid information (large blue polygon). This result is generally similar to that obtained with ENVISAT ASAR images (Fig. 2c), although with a much larger number of point scatterers, because in both cases large time intervals spanning over the winter had to be considered. On the other hand, SBAS computed over only one single season is able to detect larger rates of movements up to more than $20 \mathrm{~cm} / \mathrm{y}$ (Fig. 5b). When looking at single 11 days interferograms, as presented e.g. in Fig. 2 d, the impression is that larger slope movements should be detected but phase unwrapping failed over the active rock glaciers where rates of movements are larger than $20 \mathrm{~cm} / \mathrm{y}$. Indeed, displacement over these small landforms is often spatially incoherent, with large rock blocks moving independently on the surface, and is thus causing phase noise. Filtering of the (a) DInSAR polygons

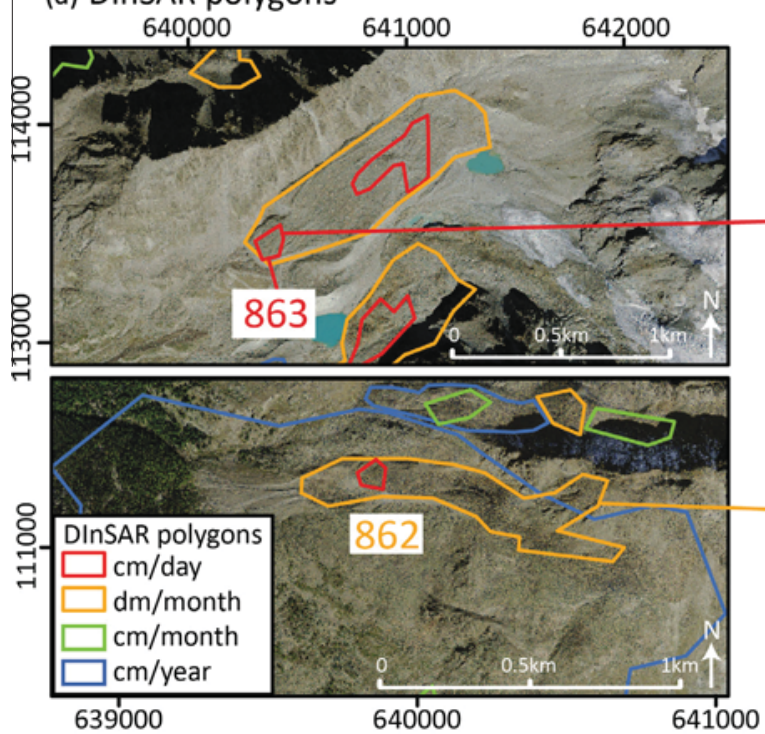

(b) Variation of slope movement's index

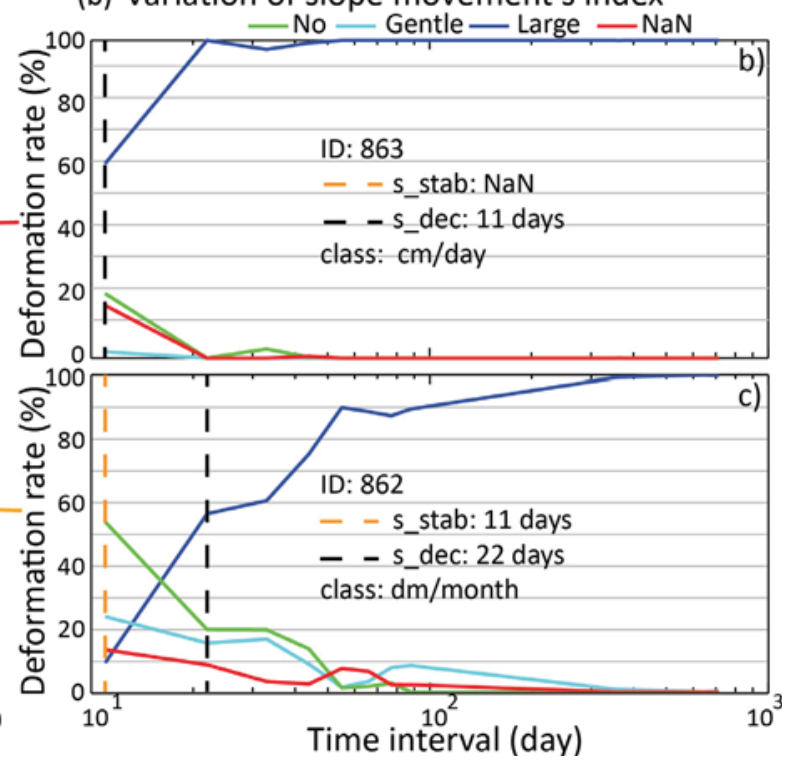

Fig. 4. (a) Localization and (b) rough estimation of deformation rate for two DInSAR polygons. The time intervals of the TerraSAR-X interferograms (Tables 1 and 3 ) are indicated with a logarithmic scale.

Table 3

Correspondence between class of velocity rate and time interval according to TSX DInSAR signal observed on the interferometric phase image.

\begin{tabular}{|c|c|c|c|c|c|c|c|c|c|c|c|c|c|c|c|c|c|}
\hline & & \multicolumn{16}{|c|}{ Time interval (day) } \\
\hline & & 11 & 22 & 33 & 44 & 55 & 66 & 77 & 88 & 352 & 363 & 374 & 638 & 649 & 660 & 704 & 715 \\
\hline \multirow[t]{4}{*}{ Classes of velocity rate } & $\mathrm{cm} /$ day & $\mathrm{n}$ & $\mathrm{n}$ & $\mathrm{n}$ & $\mathrm{n}$ & $\mathrm{n}$ & $\mathrm{n}$ & $\mathrm{n}$ & $\mathrm{n}$ & $\mathrm{n}$ & $\mathrm{n}$ & $\mathrm{n}$ & $\mathrm{n}$ & $\mathrm{n}$ & $\mathrm{n}$ & $\mathrm{n}$ & $\mathrm{n}$ \\
\hline & $\mathrm{dm} /$ month & $\mathrm{f} / \mathrm{n}$ & $\mathrm{n}$ & $\mathrm{n}$ & $\mathrm{n}$ & $\mathrm{n}$ & $\mathrm{n}$ & $\mathrm{n}$ & $\mathrm{n}$ & $\mathrm{n}$ & $\mathrm{n}$ & $\mathrm{n}$ & $\mathrm{n}$ & $\mathrm{n}$ & $\mathrm{n}$ & $\mathrm{n}$ & $\mathrm{n}$ \\
\hline & $\mathrm{cm} /$ month & f & f & $f$ & f & $f / n$ & $\mathrm{f} / \mathrm{n}$ & $f / n$ & $f / n$ & $\mathrm{n}$ & $\mathrm{n}$ & $\mathrm{n}$ & $\mathrm{n}$ & $\mathrm{n}$ & $\mathrm{n}$ & $\mathrm{n}$ & $\mathrm{n}$ \\
\hline & $\mathrm{cm} /$ year & $\mathrm{p}$ & $\mathrm{p}$ & $\mathrm{p}$ & $\mathrm{p}$ & $\mathrm{p} / \mathrm{f}$ & $\mathrm{p} / \mathrm{f}$ & $\mathrm{p} / \mathrm{f}$ & $\mathrm{p} / \mathrm{f}$ & f & $\mathrm{f}$ & f & $\mathrm{f} / \mathrm{n}$ & $\mathrm{f} / \mathrm{n}$ & $\mathrm{f} / \mathrm{n}$ & $\mathrm{f} / \mathrm{n}$ & $\mathrm{f} / \mathrm{n}$ \\
\hline
\end{tabular}

p: plain pattern, f: (partly) fringe pattern, n: noise pattern. 
interferograms was avoided to not smooth the displacement pattern and remove the signal of the largest moving parts of the unstable slopes. We anticipate nevertheless that for these landforms the phase noise represents an important tool to identify the position, extent and contour of displacements.

\subsection{Results of semi-automated texture analysis}

Fig. 6 shows the result of an automated update of the velocity rate observed for the 44 past inventoried DInSAR polygons over the study area based on TSX DinSAR data. Most of the DInSAR polygons are generally automatically classified in a faster class of velocity than the one mapped manually using ERS-1/2 and JERS-1 DInSAR data in Fig. 1. Potential false classification can immediately be pointed out for some polygons. For instance, polygon 894 located in a vegetated area, was previously moving at a deformation rate of "cm/year" and has been now classified at the rate of "cm/day". This apparent strong change of velocity rate is due to the presence of vegetation disturbing the TSX DInSAR signal and causing a noisy signal also for the shortest time interval of 11 days. In the past inventory, this area was classified as moving at "cm/year" rate based on a 3 years JERS- 1 interferogram and the same rate of movement can be observed on Fig. 5a with PSI based on TSX data. Moreover, specific attention has to be paid for polygons 869 and 870 which could potentially be incorrectly classified with a deformation rate of " $\mathrm{cm} /$ day" instead of "dm/month" due to the presence of snow cover in the upper part of the slope until late summer

\section{Validation with DGPS data}

\subsection{Available DGPS data}

Two rock glaciers, Jegi and Gruben, and the surrounding Jegi landslide located in the region of interest (Fig. 1), are seasonally surveyed by DGPS campaigns in order to analyze and understand the processes governing their kinematic. Differential GPS (DGPS) makes use of two receivers, one set up at a fixed location assumed to be motionless and one on the points of interest, in order to

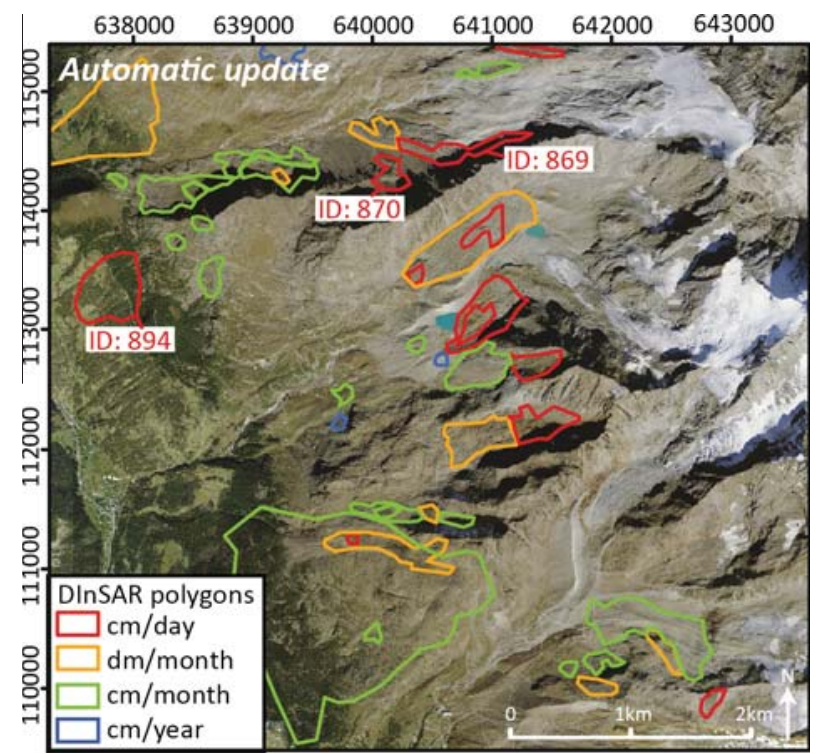

Fig. 6. Updated rates of movement obtained automatically for the 44 DInSAR polygons based on TSX data.

improve the accuracy of single measurements which are disturbed by the atmosphere (Lambiel and Delaloye, 2004). In real-time kinematic mode a rapid acquisition of data is possible, with the receiver left calculating its position for a few seconds. The standard deviation of positioning during this time lapse is usually less than $1 \mathrm{~cm}$ in the horizontal component and less than $2 \mathrm{~cm}$ in the vertical one. By adding the positioning error a total error up to $3 \mathrm{~cm}$ can be reached when comparing two sets of data (Lambiel and Delaloye, 2004).

Jegi is a $720 \mathrm{~m}$ long and $100-150 \mathrm{~m}$ wide west-oriented rock glacier located between 2450 and 2750 m a.s.l. (Fig. 7a). It consists of a rooting zone $(2700 \mathrm{~m}$ ) and a body down to a first front $(2550 \mathrm{~m})$ overriding a $150 \mathrm{~m}$ long second tongue located below. The inclination of the slope is about $20^{\circ}$ in the rooting zone, $15^{\circ}$ in the median part and the second tongue and reaches $30^{\circ}$ or more
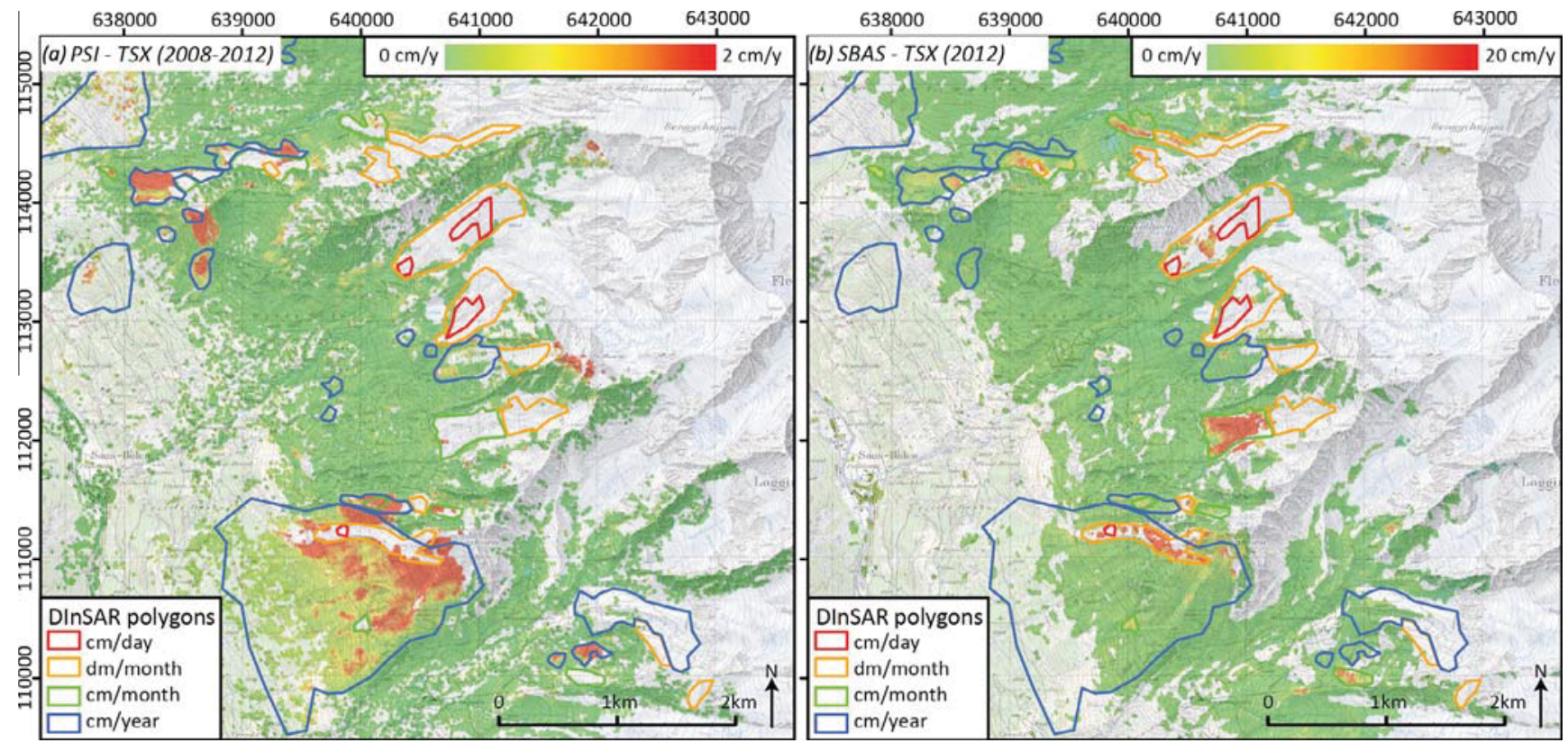

Fig. 5. Results observed with (a) PSI and (b) SBAS methods with TSX data. The polygons are those of Fig. 1 mapped manually using ERS-1/2 and JERS-1 DinSAR data. 
in the frontal parts. The rock glacier is located on a larger landslide developing mainly to the south of it (Fig. 7c). A network of 84 DGPS points covering the rock glacier and its surrounding area is measured twice a year since 2009, preferably in end of June and early October. The velocity measured by DGPS increases from a few decimeters per year in the rooting zone to $2.5-3.5 \mathrm{~m} / \mathrm{y}$ in the first frontal part, the second tongue is only moving at rate of $0.2-$ $0.5 \mathrm{~m} / \mathrm{y}$. Strong seasonal fluctuations of the velocity rate is observed over this rock glacier (Fig. 7b), however the velocity rate becomes roughly similar according to summer or winter in between 2009 and 2012. Due to the positioning error of the DGPS measurements, the velocity rate of the surrounding landslide can only be estimated from the total displacements observed between the 2009 and 2012 campaigns, corresponding to a rate of $0.015-0.035 \mathrm{~m} / \mathrm{y}$.

Gruben is a $1450 \mathrm{~m}$ long and $350 \mathrm{~m}$ wide south-west oriented rock glacier located between 2700 and $2950 \mathrm{~m}$ a.s.l. (Fig. 7d). It consists of a rooting zone formerly originating from a debriscovered glacier and a wide body down to the front. The inclination of the slope is about $5^{\circ}$ in the zone of the body and reaches $15^{\circ}$ in the frontal part. A network of 46 DGPS is also measured twice a year since 2012 (early July and early October). The velocity measured by DGPS increases from about $0.5 \mathrm{~m} / \mathrm{y}$ in the zone of the body to $1-1.2 \mathrm{~m} / \mathrm{y}$ in the frontal part. The uppermost half of the rock glacier is moving back toward the glacier (like a backcreeping push-moraine) and a significant subsidence of the surface (up to $50 \mathrm{~cm}$ ) is taking place during summer independently of the flow rate. The cause of the subsidence is probably to be sought in the presence of massive ice occurring beneath a surface blocky layer not thick enough to prevent ice melt during the summer.

\subsection{Validation of SBAS}

The SBAS performance for the monitoring of the displacement over the two rock glaciers Jegi and Gruben is evaluated with data of the summer of 2012. The displacements measured with SBAS from the complete set of 11-day TSX DInSAR from the 28th of May to the 18th of October are compared with the displacements measured from DGPS campaigns performed on the 27th of June and the 9th of October 2012 (Fig. 8). The margin of error for these DGPS measurements reaches $0.028 \mathrm{~m} / \mathrm{yr}$ in the LOS (estimated over 10 ground control points). DGPS points observed over the Jegi landslide are thus excluded. For consistency, validation is performed with DGPS absolute values of velocity projected into the TSX LOS direction.

Fig. 8 compares the SBAS and DGPS measurements and shows that there is no correlation for values larger than $0.35 \mathrm{~m} / \mathrm{yr}$ in the LOS. Above this threshold, the SBAS error increases because of phase unwrapping errors. The high value of bias expressed by the mean and the wide limit of agreements are again due to the increasing error when estimating high velocity rates and show the ambiguity of the SBAS results. Without consideration of the DGPS points moving at rates projected into the satellite LOS direction larger than $0.4 \mathrm{~m} / \mathrm{yr}$, the root mean squared error is $0.0636 \mathrm{~m} / \mathrm{yr}$ (roughly double that the DGPS imprecision).

Fig. 9 displays the positions and values of error when estimating the velocity rate with SBAS. The larger errors are found over the most active parts of the rock glaciers, where the DInSAR signal is subject to stronger decorrelation. In Fig. 9 it can be also observed that for a lot of DGPS positions there is no SBAS result, because (a) Jegi rock glacier

DGPS measurements - Horizontal flow field (Summer 2012)

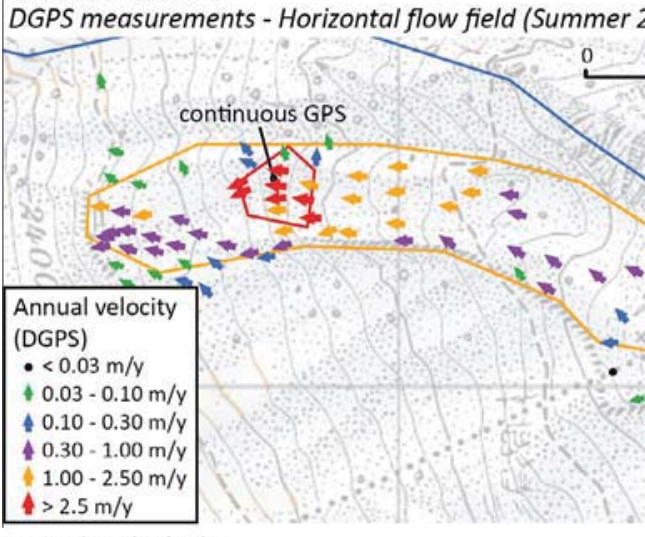

(b) Jegi rock glacier

DGPS measurements - Seasonal horizontal velocity

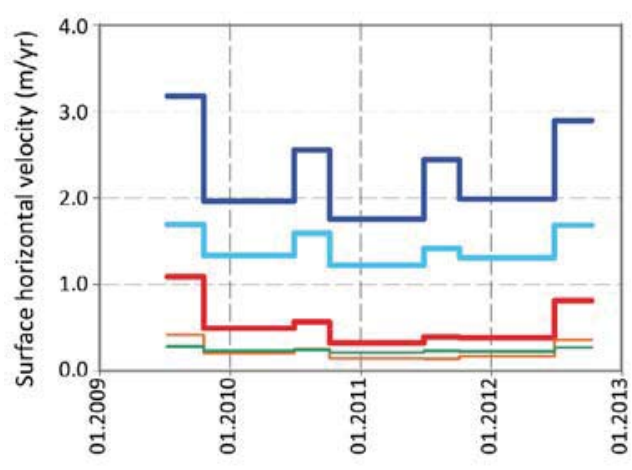

(c) Jegi landslide

DGPS measurements - Horizontal flow field (2009-2012)

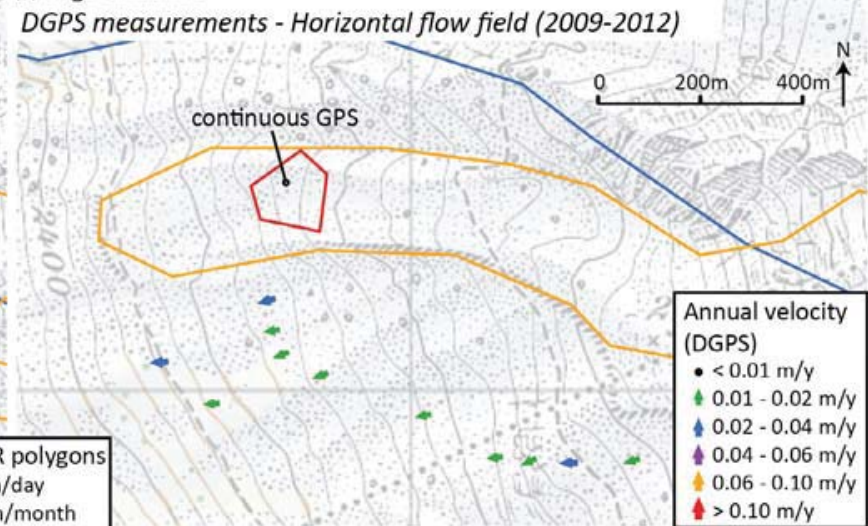

(d) Gruben rock glacier

DGPS measurements - Horizontal flow field (Summer 2012)
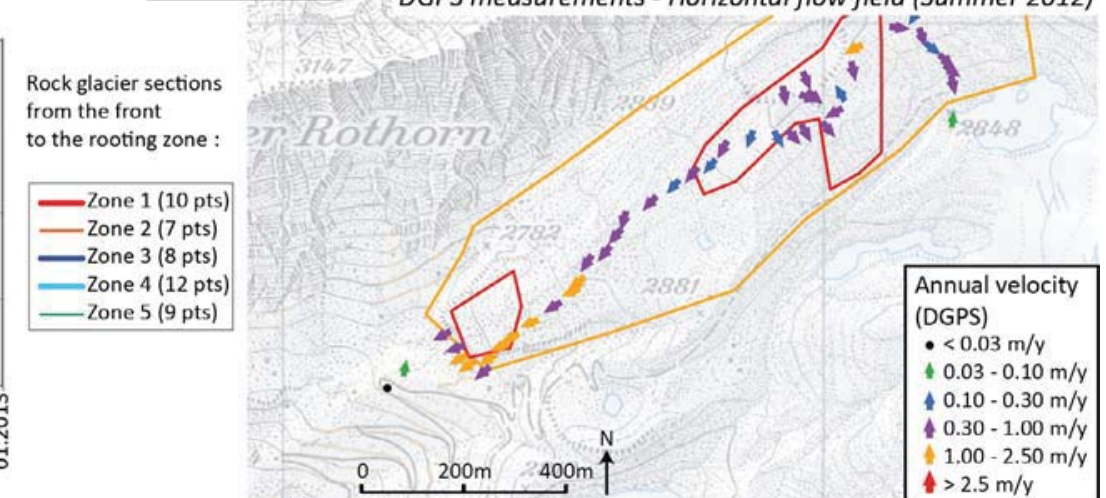

Fig. 7. (a) Horizontal flow field observed by DGPS measurements over the Jegi rock glacier during summer 2012 and (b) related seasonal horizontal velocity observed in between 2009 and 2012. (c) Horizontal flow field of the Jegi landslide derived from total displacement measured with DGPS in between 2009 and 2012. (d) Horizontal flow field observed by DGPS measurements over the Gruben rock glacier during summer 2012. 
(a) DGPS vs SBAS - 2012

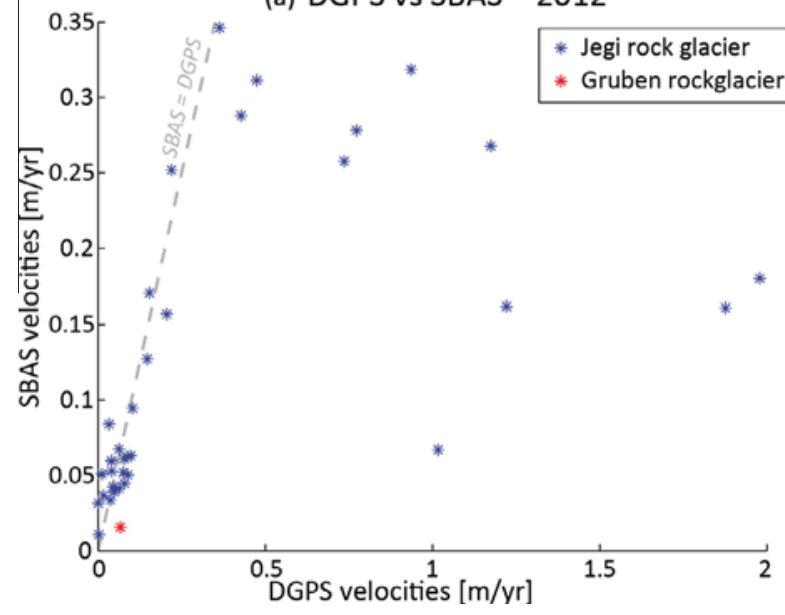

(b) DGPS vs SBAS - 2012

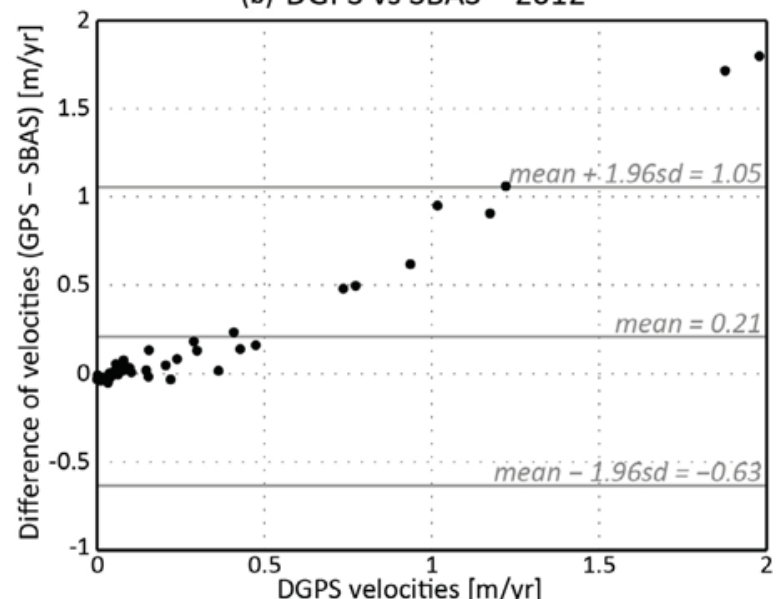

Fig. 8. Validation of SBAS measurements using DGPS measurements observed over the Jegi and Gruben rock glaciers during summer 2012. DGPS velocities are given in the satellite LOS direction.

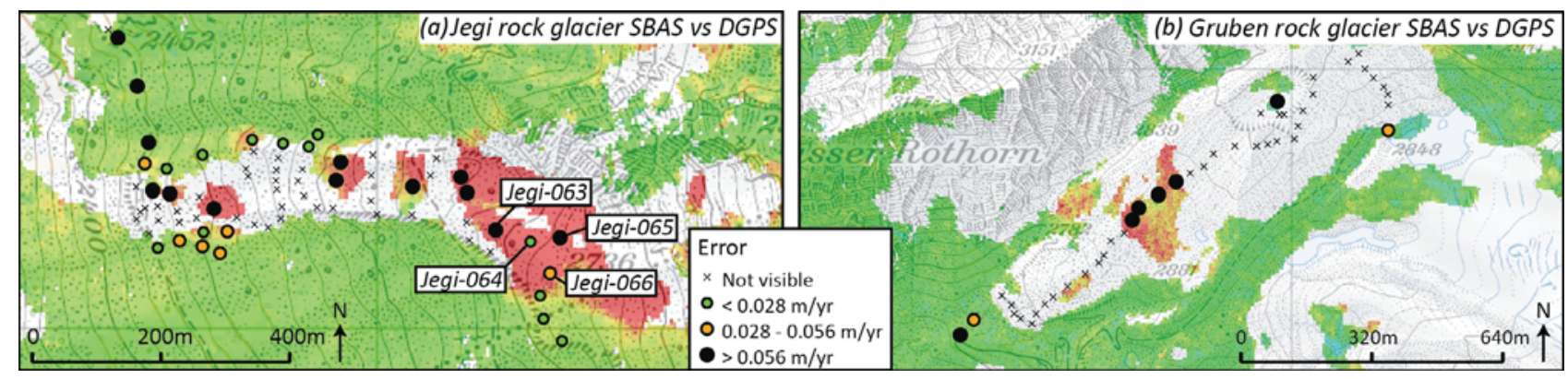

Fig. 9. Error of the SBAS method for the monitoring of displacements for each DGPS point location over the Jegi rock glacier area. Position of the points Jegi-063 to Jegi-066 used for further SBAS time series analysis is indicated.

(a) DGPS vs PSI

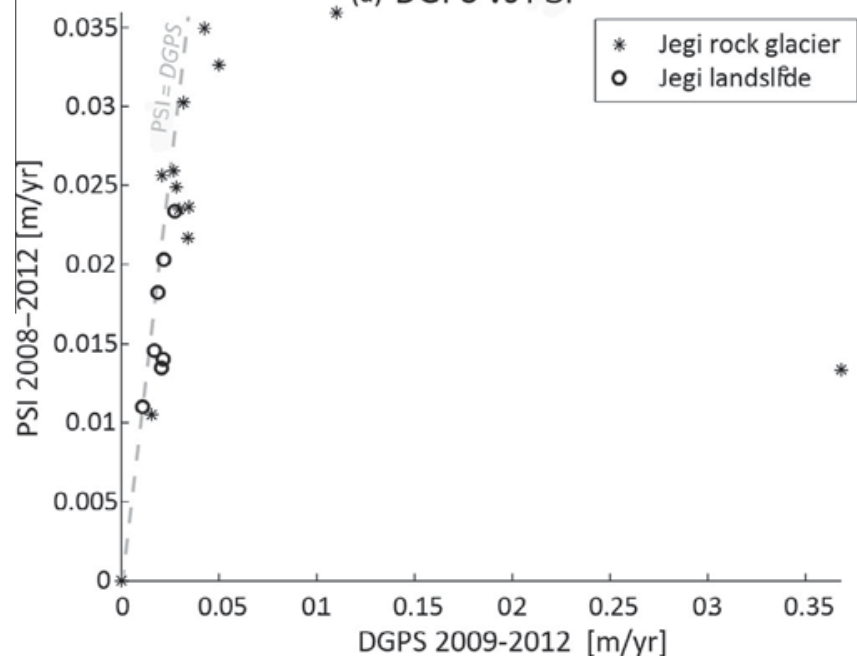

(b) DGPS (2009-2012) vs PSI (2008-2012)

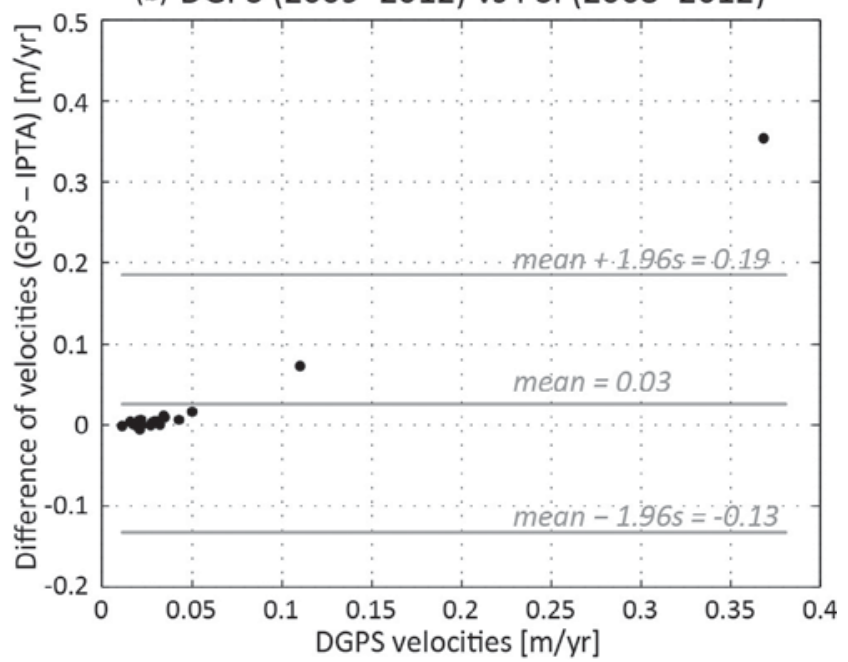

Fig. 10. Validation of PSI measurements from 2008 to 2012 using DGPS measurements from the summers of 2009 to 2012 . DGPS velocities are given in the satellite LOS direction.

of the coherence threshold of 0.4 applied to phase unwrapping. The above analysis highlights that a decrease of the coherence value to enlarge the area covered with a SBAS solution would only lead to wrong results.

\subsection{Validation of PSI}

The performance of PSI for the monitoring of displacements during the time period $2008-2012$ is evaluated using total 
displacement measured with DGPS between the 9th of July 2009 and the 9th of October 2012 over the Jegi rock glacier and landslide. The margin of error for DGPS measurements performed in between these two campaigns was estimated over 6 ground control points on stable terrain and reaches $0.19 \mathrm{~cm} / \mathrm{yr}$ in the LOS. As DGPS campaigns over the Gruben rock glacier started only in 2012, they are not used for this validation. Validation is performed with DGPS absolute values of velocity projected into the TSX LOS direction and is presented in Fig. 10.

As already seen in Fig. 5a, only slow creeping or sliding can be observed with PSI and therefore only few DGPS points mainly located over the landslide surrounding the Jegi rock glacier can be used for the validation. Fig. 10 shows an acceptable agreement between the displacements estimated from PSI and DGPS measurements when the velocity is below $3.5 \mathrm{~cm} / \mathrm{yr}$. The large values of the mean of differences and the wide limit of agreements are mainly due to the outliers with velocity larger than $3.5 \mathrm{~cm} / \mathrm{yr}$. Without consideration of these incorrect points, the root mean squared error between PSI and DGPS reaches $0.58 \mathrm{~cm} / \mathrm{yr}$.

\subsection{Validation of the semi-automated texture analysis}

The performance of the semi-automated texture analysis of interferometric phase images is evaluated for the rough estimation of the velocity rate of five DInSAR polygons detected over the Jegi and Gruben rock glaciers (Fig. 11). This rough estimation is performed using the complete TSX dataset from the summers 2008 to 2012 . As already seen in Fig. $7 \mathrm{~b}$, the summer velocity rate of the Jegi rock glacier is roughly similar in between 2009 and 2012 and confirm the possibility to use the proposed method for roughly estimate the summer velocity during this period over this rock glacier. Thus, the validation for the two polygons of the Jegi rock glacier is performed by comparing the result against the mean summer velocity rate measured with DGPS in between 2009 and 2012. Regarding the Gruben rock glacier, only the DGPS measurements from summer 2012 can be used.

Using TSX data, each of the five DInSAR polygons is automatically classified into the same class of velocity rate than existing inventory (Fig. 11b-d). By comparing the averaged 3D velocity rate
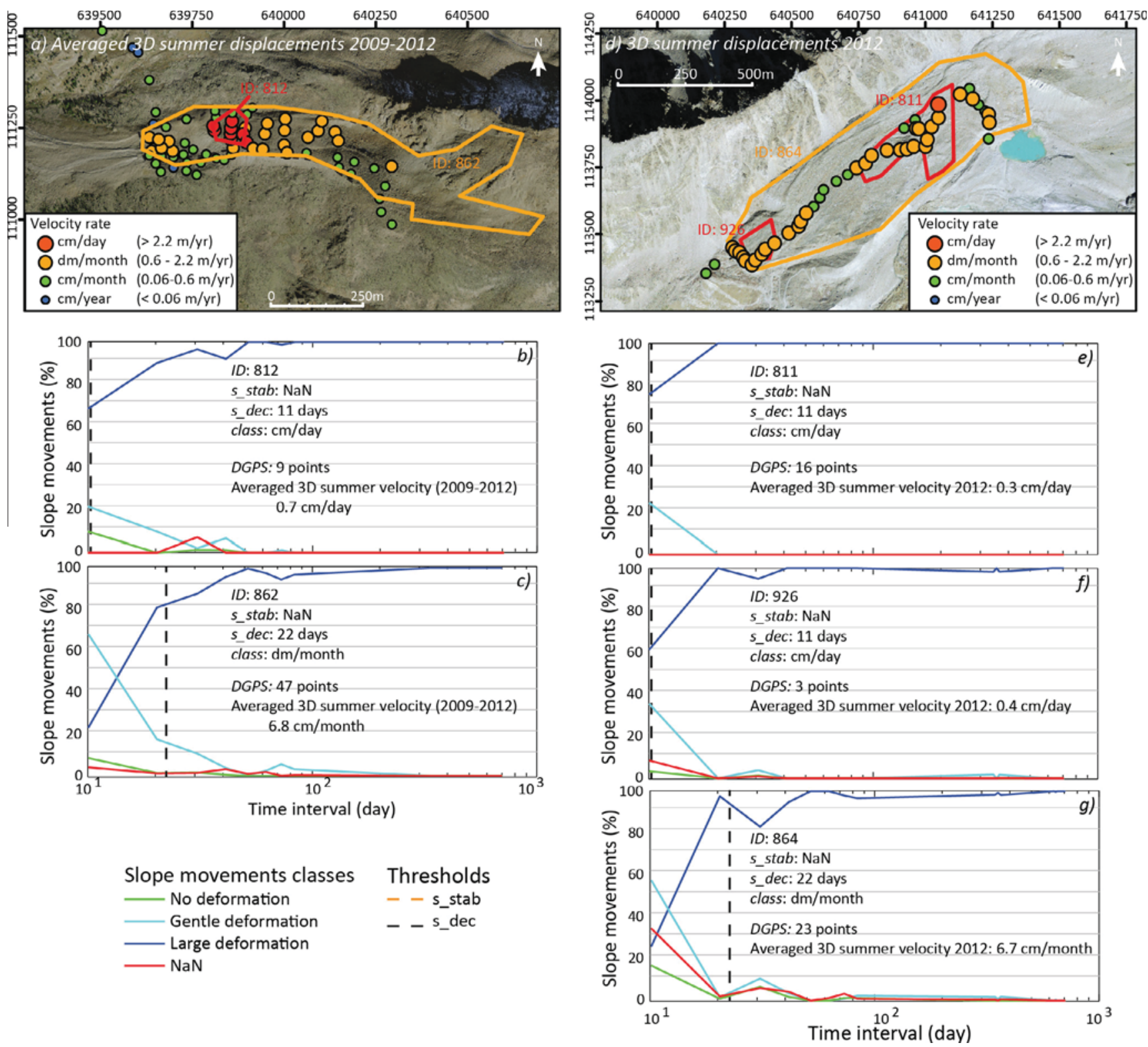

Fig. 11. (a) and (d) Averaged 3D summer velocity rates derived from DGPS measurements. (b-g) and (e-g) Comparison of the velocity rates automatically estimated over five inventoried DInSAR polygons according to the four classes of velocity: $\mathrm{cm} / \mathrm{day}, \mathrm{dm} / \mathrm{month}, \mathrm{cm} / \mathrm{month}$ and $\mathrm{cm} /$ year. 
measured from DGPS measurements over each of these polygons, it appears that the two delineated polygons of the Jegi rock glacier are correctly classified: the polygon 812 (Fig. 11b) is described by 9 DGPS points having an average 3D velocity of $0.7 \mathrm{~cm} /$ day between 2009 and 2012 (class "cm/day"), and the polygon 862 (Fig. 11c) is described by 47 points moving with an average velocity rate of $6.8 \mathrm{~cm} /$ month (class "dm/month"). The polygon 864 of the Gruben rock glacier (Fig. $11 \mathrm{~g}$ ) is also correctly classified: the averaged 3D velocity between 2012 and 2013 is about $6.7 \mathrm{~cm} / \mathrm{month}$, which corresponds to the "dm/month" class. However, the two fastest DInSAR polygons of the Gruben rock glacier (Fig. 11e and f) are not correctly classified: the average velocity of 0.3 and $0.4 \mathrm{~cm} /$ day given by the DGPS measurements is too low compared to the class of deformation "cm/day" that was automatically estimated. The difference observed over the Gruben rock glacier may be explained by the non-coincident in time of DGPS and DInSAR measurement but also by the fact that the outline of the polygon may have to be updated. Thus, the validation of the presented methodology over this rock glacier has to be carefully interpreted.

\section{Discussion}

\subsection{Observable velocity rate using PSI and SBAS}

Our results allow us to indicate where and when the application of each of the presented advanced SAR processing methods using a large TSX dataset is applicable for the detection and mapping of various slope movements encountered in Alpine environments. As indicated in many past studies, PSI is a powerful method to observe slow slope movements with a very high sensitivity in the $\mathrm{mm} / \mathrm{year}$ scale (e.g. Crosetto et al., 2007; Raucoules et al., 2009). However, our work has also shown that the higher spatial resolution and the shorter revisiting time of TSX used with PSI over a time span of five years do not provide significantly more benefits than other sensors for the observation of slope movement faster than $3.5 \mathrm{~cm} / \mathrm{yr}$. This is mainly due to the fact that only SAR images acquired during the snow-free period from June to October can be considered in the analysis. SBAS employed with 11 days summer interferograms increases the range of detectable movements to rates of up to $35 \mathrm{~cm} / \mathrm{yr}$. However, errors due to phase unwrapping are already possible for velocity rates larger than $20 \mathrm{~cm} / \mathrm{yr}$. Similar problems were also observed in the case of mining (Spreckels et al., 2001; Przylucka et al., 2015), where undersampling of the SAR data in relationship to the large rates of movement caused phase unwrapping errors.

Semi-automated texture analysis was developed to be an alternative to PSI and SBAS in the case of rapidly moving landforms with velocities larger than about $20 \mathrm{~cm} / \mathrm{yr}$. The validation of this methodology with DGPS measurements could be performed only for a very limited number of moving areas (5 polygons). Therefore, a further validation of this automated method was performed against the visual interpretation of the TSX DInSAR data with respect to the 44 DInSAR polygons previously detected on our study site.

\subsection{Visual interpretation of TSX DInSAR and validation of the semi-automated texture analysis}

A methodology for the visual upgrade is proposed in the work of Barboux (2014) as an adaption of the core methodology for slope movement inventory detailed in Barboux et al. (2014) and would aim to (a) identify the new moving landforms over the region, (b) spatially renew the outline of the past inventoried DInSAR polygons, (c) categorize (or update) the deformation rate of the detected DInSAR polygons and (d) eliminate possible errors (or no longer moving areas) of the past inventories. Fig. 12a shows the visual upgrade of the studied area with TerraSAR-X following this methodology. Many DInSAR polygons have been separated into different objects and numerous new moving objects were found thanks to the high spatio-temporal resolution of TSX data. Few new moving landforms have also been identified. The validation of the automatically updated inventory against the manual interpretation is performed in terms of velocity rate classification whatever the change of the outline of the considered DInSAR polygon. The confusion matrix related to the classification of velocity rate (Table 4) indicates the number of past inventoried DInSAR polygons assigned to a class of velocity rate by the automated process against the reference class of velocity rate visually interpreted. An additional class "-" is defined for past inventoried DInSAR polygons no longer visually detectable with the newer TSX DInSAR data.

Overall, the average error of the automatic update with respect to the manual one is 0.68 with a kappa index of 0.58 showing a moderate agreement. It has to be noted that a change of the thresholds used to identify s_stab and s_dec (for instance a proportion of respective patterns higher than $40 \%$ or $60 \%$ ) does not imply a change in the final automated velocity rate classification. Indeed, the period between $s_{-} s t a b$ and $s_{-}$dec, representing the time intervals where (partly) fringe pattern representing gentle deformation can be observed, is simply extended or reduced while staying centered on the same range of time intervals and thus the same final

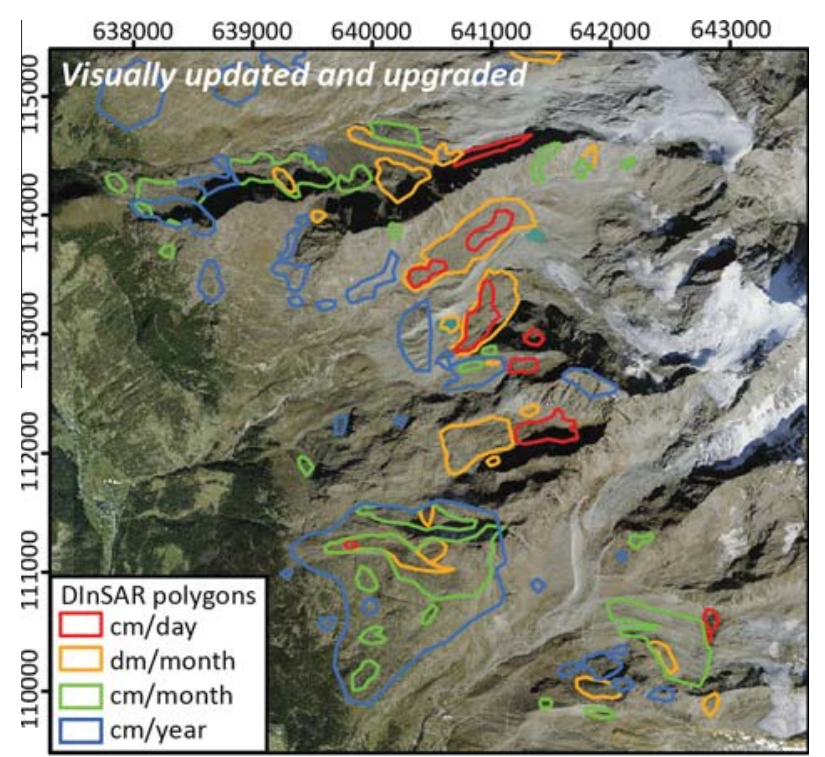

Fig. 12. Result of the visual update and upgrade (outlines and velocity rate) of the 44 past inventoried DInSAR polygons.

\section{Table 4}

Confusion matrix between automatic and manual velocity rate classification of the past inventoried DInSAR polygons in the region of interest. Each column represents the occurrence in the predicted class (automated), while each row represents the visually observed occurrence in each class (reference).

\begin{tabular}{llrllllll}
\hline & & \multicolumn{6}{c}{ Automatically classified as } \\
\cline { 3 - 8 } & & & $\mathrm{cm} / \mathrm{d}$ & $\mathrm{dm} / \mathrm{m}$ & $\mathrm{cm} / \mathrm{m}$ & $\mathrm{cm} / \mathrm{y}$ & - \\
\hline \multirow{2}{*}{ Visually classified as } & $\mathrm{cm} / \mathrm{d}$ & 6 & $\mathbf{6}$ & 0 & 0 & 0 & 0 \\
& $\mathrm{dm} / \mathrm{m}$ & 13 & 5 & $\mathbf{8}$ & 0 & 0 & 0 \\
& $\mathrm{~cm} / \mathrm{m}$ & 12 & 0 & 0 & $\mathbf{1 2}$ & 0 & 0 \\
& $\mathrm{~cm} / \mathrm{y}$ & 11 & 0 & 1 & 6 & $\mathbf{3}$ & 0 \\
& - & 2 & 1 & 0 & 1 & 0 & $\mathbf{0}$
\end{tabular}

Ao: $0.68, \mathbf{k}: 0.58$

The total number of visually classified classes is given in italic, correct automatic classification is indicated in bold. 
classification of velocity rate is identified. Misclassification of the automatic update to a faster class of velocity is the most common error. This is mainly due to the detection and interpretation of the DInSAR signal as noise pattern on a shorter time interval than it should be caused by the presence of noise. In particular the yearly TerraSAR-X interferograms are largely decorrelated over mountain regions due to the presence of vegetation, snow or atmosphere as disturbing external effects and thus the estimation of the " $\mathrm{cm} / \mathrm{y}$ " velocity rate class is most of the time not accurate. In other cases decorrelation is also due to border effects in neighboring areas, large seasonal variations in the deformation and changes over time in the outline of the landform. In the case of doubts, visual interpretation of single interferograms is required to correctly determine the right class of velocity.

As a summary, the comparison between automatic and manual classification as well as the validation of the automatic approach with DGPS indicate that the rough estimation of velocity rate over an outlined moving zone is accurate for velocity rates of " $\mathrm{cm} /$ day", "dm/month" and "cm/month", i.e. for velocities larger than about $10 \mathrm{~cm} / \mathrm{y}$. However, due to the decorrelation of yearly TSX interferograms, this method is not accurate for the observation of slow movements ("cm/y"). Regarding fast velocities, the class " $\mathrm{cm} /$ day" is by definition given to each polygons showing DInSAR signal decorrelated on 11 day TSX interferograms. This means that velocities faster than some centimeters per day are encompassed in this class.

\subsection{Monitoring the temporal variability in rock glacier kinematics}

Superimposed to the decennial trend that can be observed in rock glacier surface motion there is also a seasonal rhythm (Delaloye et al., 2010). Recently installed continuous GPS sensors, as the one put in place over the higher front of the Jegi rock glacier on August 2012 (Fig. 7), indicate that the lowest velocities are generally observed in spring or early summer and the highest velocities are reached in most cases between summer and early winter with a maximum of velocity in autumn (Fig. 13). An additional

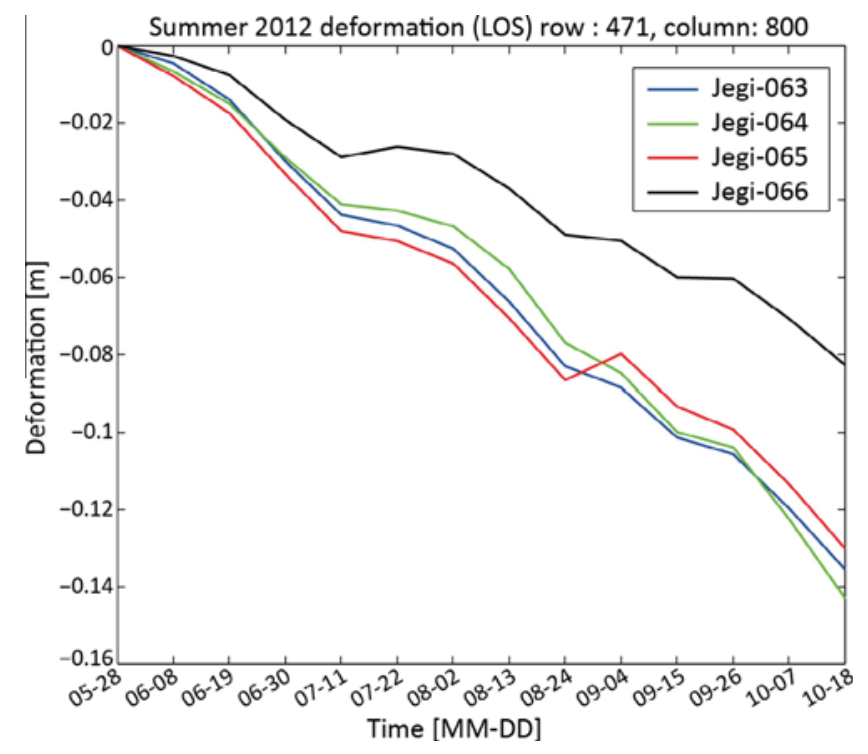

Fig. 14. SBAS time series for the summer 2012 for the points Jegi-063 to jegi-066 over the Jegi rock glacier. For position see Fig. 9a.

short peak in velocity can also occur during the snowmelt phase end of spring and the maximum of velocity is observed in autumn. This typical intra-annual variability is also observed from different GPS stations located around this rock glacier (Wirz et al., 2015).

Whereas the contribution of SAR Interferometry for the observation of decennial trend or interannual variations was demonstrated in the previous sections, the feasibility of SAR interferometry for the observation of intra-seasonal fluctuations remains to be confirmed. Past studies have suggested that the acquisition time intervals of SAR data allows the detection of significant temporal and spatial variability of rock glacier velocities (Nagler et al., 2001), but other authors suggest more specific attention during interpretation of unique interferograms which might

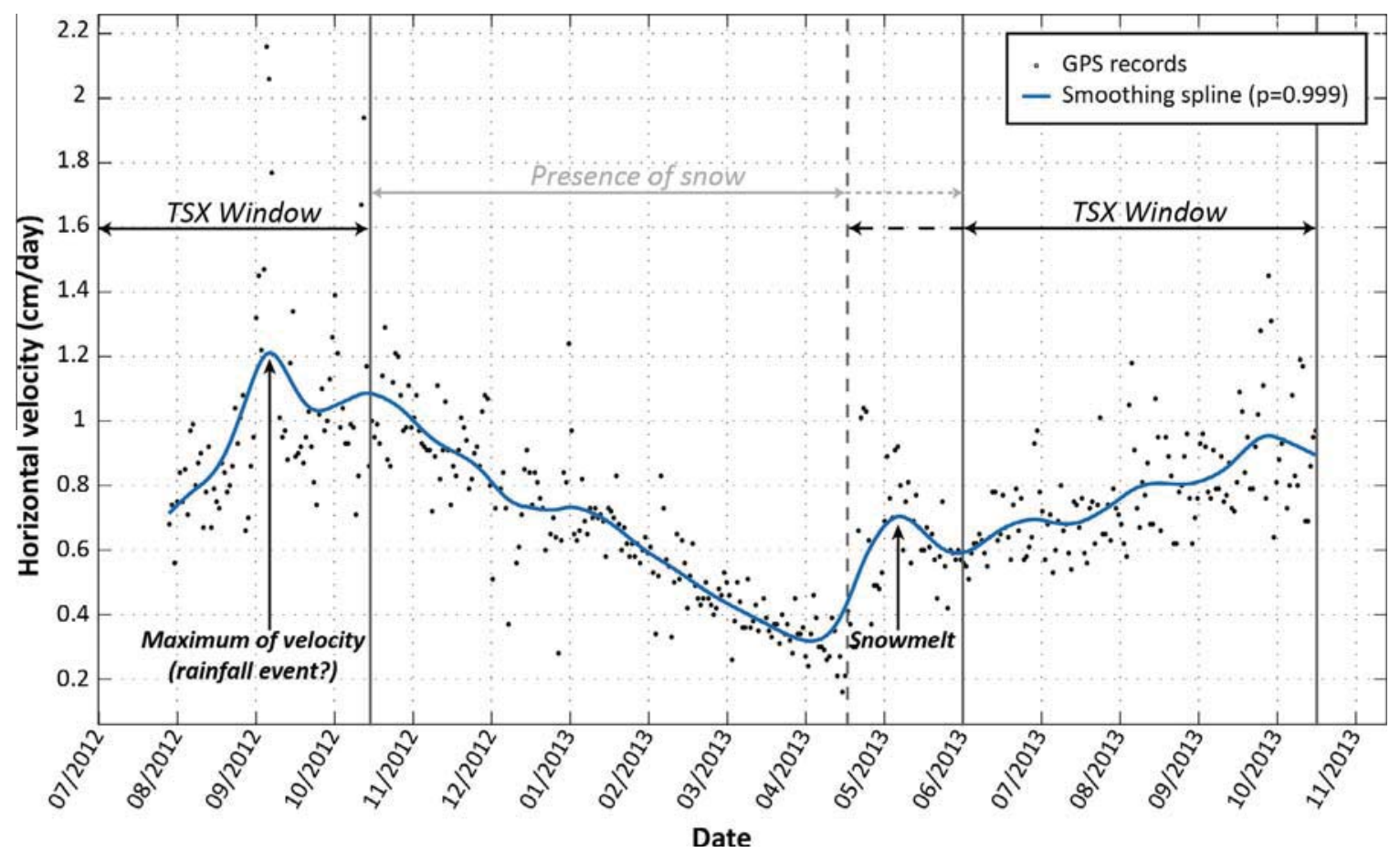

Fig. 13. Horizontal velocity (cm/day) from continuous GPS located on Jegi rock glacier. For position see Fig. 7. 
be affected by atmospheric artifacts (Kenyi and Kaufmann, 2003). The SBAS methodology allows the reconstruction of the temporal evolution of movement, Fig. 14 gives an example of time series deformation for the points jegi-063, jegi-064, jegi-065 and jegi-066 that are located over the wide body of the Jegi rock glacier (for position see Fig. 9a). The four points show similar behavior with moderate changes in deformation rate, and stronger displacement observed in 11 days at the end of June - beginning of July and in August. The lack of significant fluctuations can be explained by the fact that this part of the rock glacier is maybe not subject to different rates of strong acceleration during the season (Fig. 7b, zone 5). But it has to be also considered that SBAS measurements are restricted to rates slower than about $20 \mathrm{~cm} / \mathrm{y}$, which seems not to be suitable for the observation of seasonal fluctuations over this active rock glacier (rate detected with continuous GPS larger than $1 \mathrm{~m} / \mathrm{yr}$, Fig. 13).

Visual interpretation of each snow-free 11 days interferogram available during the summer 2012 reveals a substantial variation of the DInSAR signal on the first front and the second tongue of the Jegi rock glacier (Fig. 15c, e, g, and i). Thus, we suggest the
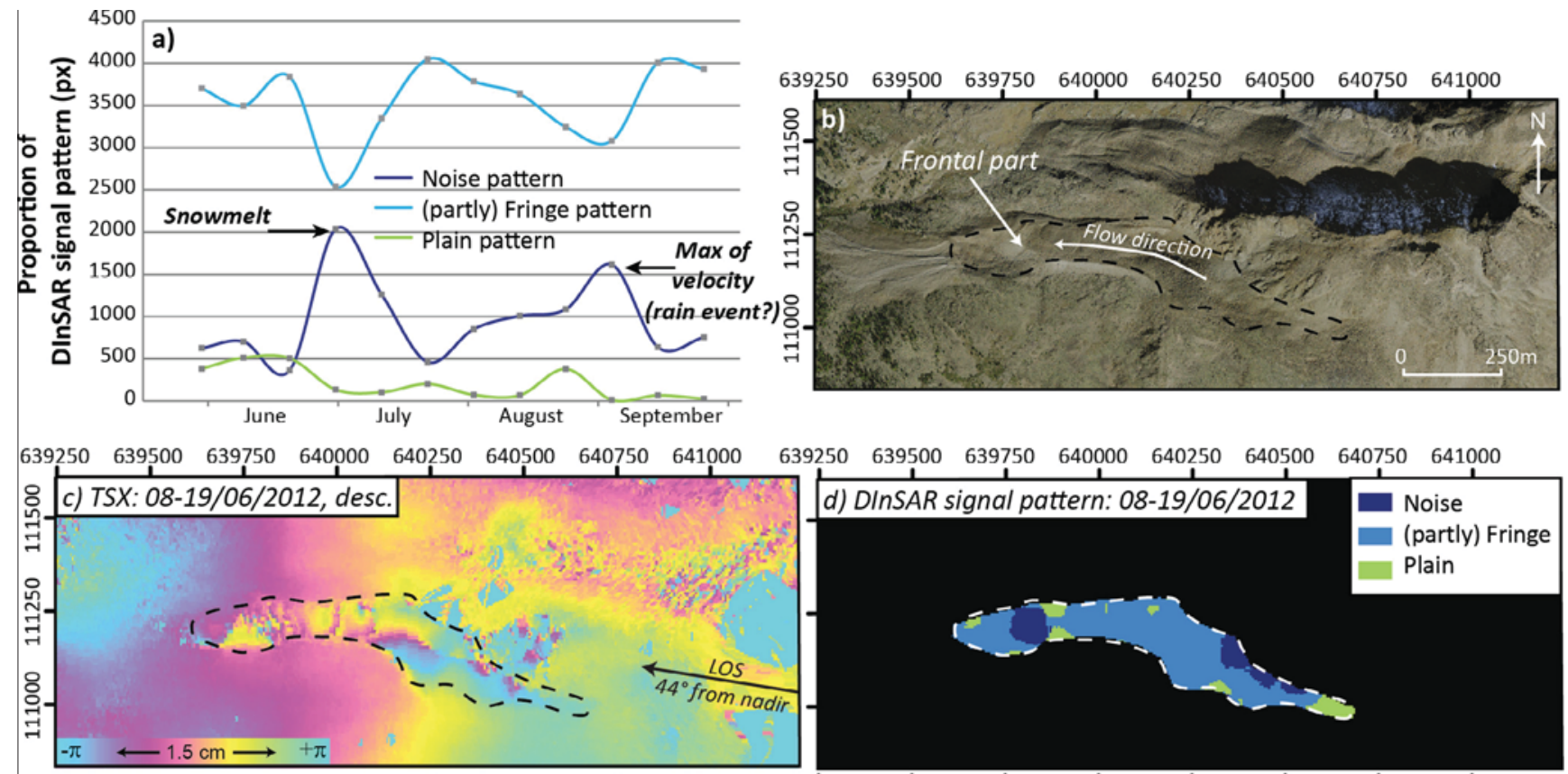

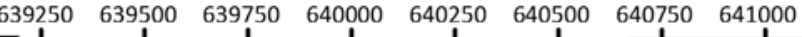
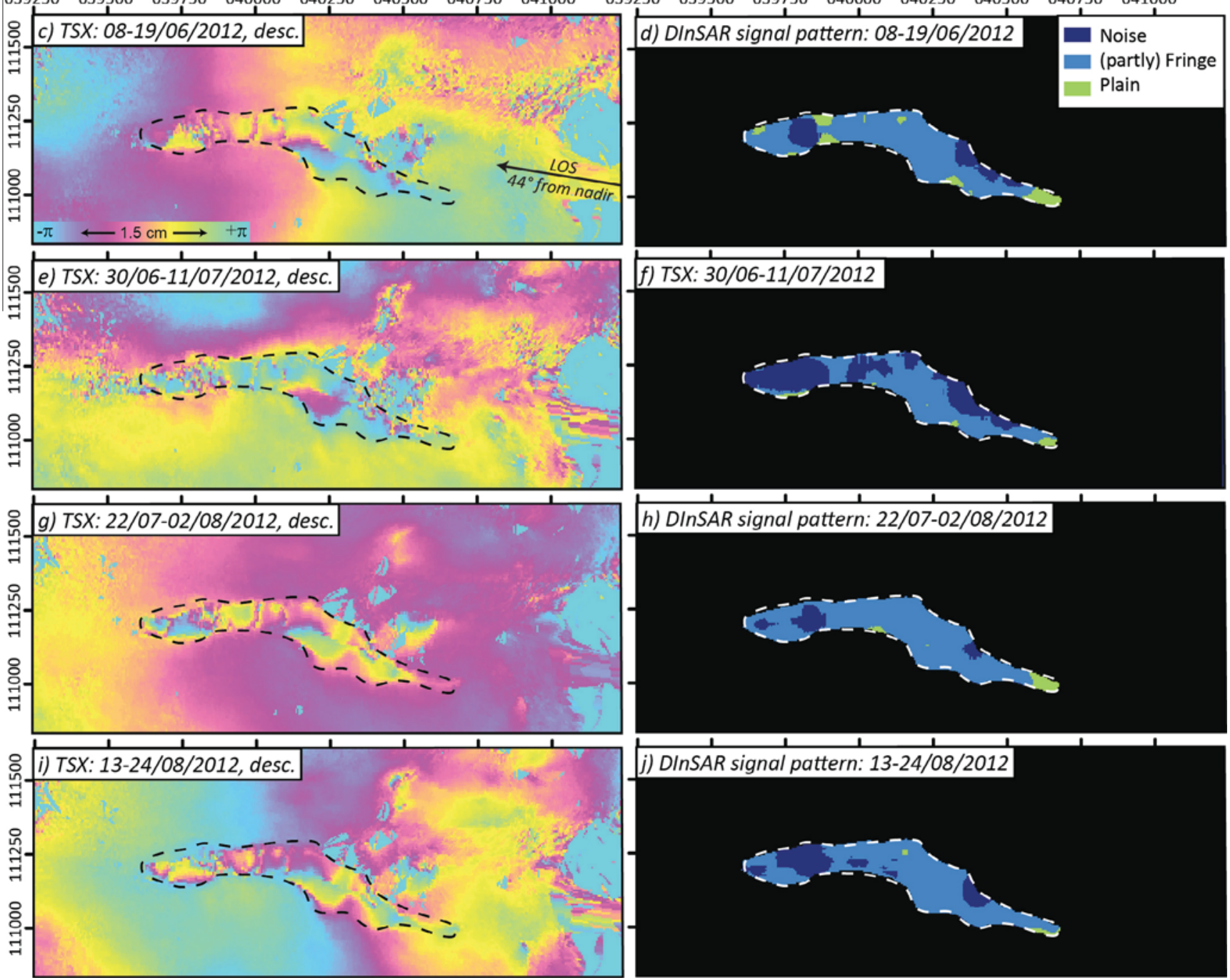

Fig. 15. (a) Seasonal behavior of the DInSAR signal patterns observed on Jegi rock glacier in 2012. (b) Orthoimage of the Jegi rock glacier with the outline observed area drawn as dotted lines. $(\mathrm{c}-\mathrm{j})$ Interferometric phase images and corresponding automated DInSAR. 
use of consistent series of TSX interferograms for the automatic survey of the seasonal rhythm of rock glaciers. Fig. 15 presents the results of the semi-automated texture analysis of each of the DInSAR signal patterns during summer 2012. A first single peak of noise pattern (and respective drop of (partly) fringe pattern) is observed at the end of June (Fig. 15a) and can be related to the increase in the activity over the frontal part of the rock glacier that can also been observed on the interferometric phase image (Fig. 15e). Then an increase of the noise pattern (and respective decrease of the fringe pattern) is gradually observed during the summer with a maximum of velocity reached in September suggesting an increase in the activity of the rock glacier dynamic as observed with continuous GPS (Fig. 13).

The main advantage of the analysis based on DInSAR data is to provide information about the evolution in time for the spatial extent of the deformation rate. Compared to GPS, both continuous and differential, the whole surface of the landform is systematically analyzed with DInSAR. But attention is required to accurately interpret the specific processes governing the landform, because drops in the interferometric coherence might be also caused by snow fall, rain fall events, etc. For instance, the short peak of velocity observed in September 2012 (Figs. 13 and 15) may be related to heavy rain events causing a heterogeneous movement of surface boulders rather than an acceleration of the whole rock glacier during this short period. It is therefore suggested to combine the DInSAR observation with external data like weather forecast in order to give reliable interpretation about the specific processes governing the rock glacier movement.

\section{Conclusions}

The methods of PSI, SBAS and semi-automated texture image analysis were compared in order to determine their contribution for the automatic detection and mapping of slope movements having various velocity rates based on TerraSAR-X images. Investigations were conducted in the Alpine environment of the Western Swiss Alps using 140 interferograms computed from 51 summer acquisitions from 2008 to 2012 . We found that PSI is able to precisely detect only points moving with velocities below $3.5 \mathrm{~cm} / \mathrm{yr}$ in the LOS, with a root mean squared error of about $0.58 \mathrm{~cm} / \mathrm{yr}$ compared to DGPS records. SBAS employed with 11 days summer interferograms increases the range of detectable movements to rates of up to $35 \mathrm{~cm} / \mathrm{yr}$ in the LOS with a root mean squared error of $6.36 \mathrm{~cm} / \mathrm{yr}$, but inaccurate measurements due to phase unwrapping are already possible for velocity rates larger than $20 \mathrm{~cm} / \mathrm{yr}$. With the semi-automated texture image analysis the rough estimation of the velocity rates over an outlined moving zone is accurate for rates of " $\mathrm{cm} /$ day", " $\mathrm{dm} / \mathrm{month"} \mathrm{and}$ "cm/month", but due to the decorrelation of yearly TSX interferograms this method fails for the observation of slow movements in the " $\mathrm{cm} / \mathrm{y}$ " range. The above considerations suggest that the combination of the three methods would allow the correct detection and mapping of various kinds of slope movements that can be encountered in Alpine environment.

Regarding fast velocities, the class "cm/day" is by definition given to each polygons showing DInSAR signal decorrelated on 11 day TSX interferograms. This means that velocities faster than some centimeters per day are encompassed in this class. The distinctions of further velocity classes, as required by the definition of Varnes (1978), would be certainly feasible with acquisitions from the Cosmo-SkyMed constellation (ASI, 2007), but interferograms acquired with 4 days time interval over the studied region are rare. Other possibilities to spatially detect rates of movement of more than $1 \mathrm{~cm} /$ day are given by terrestrial radar interferometers, which permit acquisitions with a sampling rate of a few minutes (Strozzi et al., 2015), by using sub-pixel offset techniques on SAR amplitude images (Manconi et al., 2014; Singleton et al., 2014), but very high-resolution is required to detect small scale instabilities, and by considering L-band PSI (Bianchini et al., 2013), which was not possible in our case because only six ALOS PALSAR images were acquired over the snow-free period. Shorter revisit time of the radar acquisitions would also permit to increase the performance of presented methods for the detection of seasonal variations of the rock glacier dynamics, which is very limited with TerraSAR-X data.

The presented semi-automated method based on texture image analysis only provides an update of existing inventories by detecting a change in the activity rate for past outlined moving area ("DInSAR polygons"). A methodology for the visual upgrade is proposed in the discussion in order to validate the semi-automated texture analysis. In that case, the automated slope movement mapping can be suggested as a useful tool for visually interpreting DInSAR data, especially when using a large SAR dataset, in order to perform an accurate up-to-date inventory and reducing the subjectivity of the operator. An automatic upgrade of existing slope movement inventory (update of outlines and detection of new polygons) was however not investigated in this paper but may be investigated through different mathematical tools used in image processing for feature detection and extraction. For such an analysis it is important to define also a confidence degree to be applied to each classified polygon and its velocity class. SAR data from the recently launched Sentinel- 1 mission could be used in addition to TerraSAR-X data, providing regular acquisitions with a 12 days time interval with an increased sensitivity to movement because of the larger wavelength but at a lower spatial resolution.

\section{Acknowledgments}

TERRASAR-X Data are courtesy of LAN041, LAN1145 and LAN2548 (c) DLR; SwissAlti3D is copyright 2011 Swisstopo, Swissimages \& Pixel Maps 25 are copyright 2010 of Swisstopo (5701137809/000410 \& /000010).

\section{References}

Agenzia Spaziale Italiana, 2007. COSMO-SkyMed System Description \& User Guide. Doc. No. ASI-CSM-ENG-RS-093-A. ASI, Agenzia Spatiale Italiana, Roma, Italy.

Bamler, R., Hartl, P., 1998. Synthetic aperture radar interferometry. Inverse Prob. 14, R1-R54.

Barboux, C., Delaloye, R., Strozzi, T., Lambiel, C., Collet, C., Raetzo, H., 2012. Monitoring active rock glaciers in the Western Swiss Alps: challenges of differential SAR interferometry and solution to estimate annual and seasonal displacement rates. In: Proc. IGARSS 2012, Munich, Germany, 22-27 July 2012.

Barboux, C., Reynald, D., Christophe, L., Tazio, S., Hugo, R., Claude C., 2013. Semiautomated detection of terrain activity in the Swiss Alpine periglacial environment from DInSAR scenes. In: Proc. ESA Living Planet Symposium, Edimburgh, Scotland, 9-13 September 2013.

Barboux, C., Delaloye, R., Lambiel, C., 2014. Inventorying of slope movement in Alpine environment using DInSAR. Earth Surf. Proc. Land. 39 (15), 2087-2099. http://dx.doi.org/10.1002/esp.3603.

Barboux, C., 2014. Detection, Mapping and Monitoring of Slope Movements in the Alpine Environment using DInSAR. PhD Thesis, Department of Geosciences, Geography, University of Fribourg.

Berardino, P., Fornaro, G., Lanari, R., Sansosti, E., 2002. A new algorithm for surface deformation monitoring based on Small Baseline Differential SAR interferograms. IEEE Trans. Geosci. Remote Sens. 40, 2375-2383. http://dx. doi.org/10.1109/TGRS.2002.803792.

Bianchini, S., Herrera, G., Mateos, R.M., Notti, D., Garcia, I., Mora, O., Moretti, S., 2013. Landslide activity maps generation by means of persistent scatterer interferometry. Remote Sensing 5, 6198-6222. http://dx.doi.org/10.3390/ rs5126198.

Cascini, L., Fornaro, G., Peduto, D., 2010. Advanced low- and full-resolution DInSAR map generation for slow-moving landslide analysis at different scales. Eng Geol. 112 (1-4), 29-42. http://dx.doi.org/10.1016/j.enggeo.2010.01.003.

Colesanti, C., Wasowski, J., 2006. Investigating landslides with space-borne Synthetic Aperture Radar (SAR) interferometry. Eng. Geol. 88, 173-199. http://dx.doi.org/10.1016/j.enggeo.2006.09.013.

Bovenga, F., Wasowski, J., Nitti, D., Nutricato, R., Chiaradia, M.T., 2012. Using COSMO/SkyMed X-band and ENVISAT C-band SAR interferometry for landslides 
analysis. Remote Sens. Environ. 119, 272-285. http://dx.doi.org/10.1016/j. rse.2011.12.013.

Crosetto, M., Agudo, M., Monserrat, O., Pucci, B., 2007. Inter-comparison of persistent scatterer interferometry results. In: Proc. Fringe 2007 Workshop, Frascati, Italy, 26-30 November 2007.

Delaloye, R., Lambiel, C., Lugon, R., Raetzo, H., Strozzi T., 2007. ERS InSAR for detecting slope movement in a periglacial mountain environment (Western Valais Alps, Switzerland). In: Proc. HMRSC-IX, Grazer Schriften der Geographie und Raumforschung, 43, pp. 113-120.

Delaloye, R., Lambiel, C., Gärtner-Roer, I., 2010. Overview of rock glacier kinematics research in the Swiss Alps. Geogr. Helv. 65, 135-145. http://dx.doi.org/10.5194| gh-65-135-2010.

Farina, P., Colombo, D. Fumagalli, A., Marks, F., Moretti, S., 2006. Permanent scatterers for landslide investigations: outcomes from the ESA-SLAM project. Eng. Geol. 88, 200-217. http://dx.doi.org/10.1016/j.enggeo.2006.09.007.

Ferretti, A., Prati, C., Rocca, F., 2001. Permanent scatterers in SAR interferometry. IEEE Trans. Geosci. Remote Sens. 39, 8-20. http://dx.doi.org/10.1109/ 36.898661 .

García-Davalillo, J.C., Herrera, G., Notti, D., Strozzi, T., Álvarez-Fernández, I., 2014 DinSAR analysis of ALOS PALSAR images for the assessment of very slow landslides: the Tena Valley case study. Landslides 11 (2), 225-246. http://dx doi.org/10.1007/s10346-012-0379-8.

Goldstein, R., Werner, C., 1998. Radar interferogram filtering for geophysical applications. Geophys. Res. Lett. 21, 4035-4038. http://dx.doi.org/10.1029/ 1998GL900033.

Herrera, G., Notti, D., Garcia-Davalillo, J.C., Mora, O., Cooksley, G., Sanchez, M., Arnaud, A., Crosetto, M., 2010. Landslides analysis with C- and X-band satellite SAR data: the Portalet landslide area. Landslides 8 (2), 195-206. http://dx.doi. org/10.1007/s10346-010-0239-3.

Kenyi, L.W., Kaufmann, V., 2003. Estimation of rock glacier surface deformation using SAR interferometry data. IEEE Trans. Geosci. Remote Sens. 41 (6), 1512 1515.

Lambiel, C., Delaloye, R., 2004. Contribution of real-time kinematic GPS in the study of creeping mountain permafrost: examples from the Western Swiss Alps. Permafrost Periglac. Process. 15, 229-241. http://dx.doi.org/10.1002/ppp.496.

Lambiel, C., Delaloye, R., Strozzi, T., Lugon, R., Raetzo, H., 2008. ERS InSAR for assessing rock glacier activity. In: Proc. 9th Int. Conference on Permafrost, Fairbanks, Alaska, USA, 29 June-03 July 2008, pp. 1019-1025.

Lanari, R., Mora, O., Manunta, M., Mallorqui, J., Berardino, P., Sansosti, E., 2004. A small baseline approach for investigating deformations on full resolution differential SAR interferograms. IEEE Trans. Geosci. Remote Sens. 42 (7), 1377 1386. http://dx.doi.org/10.1109/TGRS.2004.828196.

Lauknes, T.R., Piyush Shanker, A., Dehls, J., Zebker, H., Henderson, I., Larsen, Y., 2010. Detailed rockslide mapping in northern Norway with small baseline and persistent scatterer interferometric SAR time series methods. Remote Sens. Environ. 114 (9), 2097-2109. http://dx.doi.org/10.1016/j.rse.2010.04.015.

Lee, C.W., Lu, Z., Jung, H.S., Won, J.S., Dzurisin, D., 2010. Surface Deformation of Augustine Volcano (Alaska), 1992-2005, From Multiple-Interferogram Processing Using a Refined SBAS InSAR Approach. USGS Professional Papers 1769, pp. 453-465.

Manconi, A., Casu, F., Ardizzone, F., Bonano, M., Cardinali, M., De Luca, C., Gueguen, E., Marchesini, I., Parise, M., Vennari, C., Lanari, R., Guzzetti, F., 2014. Brief communication: Rapid mapping of landslide events: the 3 December 2013 Montescaglioso landslide, Italy. Nat. Hazards Earth Syst. Sci. 14, 1835-1841. http://dx.doi.org/10.5194/nhess-14-1835-2014.

Meisina, C., Zucca, F., Notti, D., Colombo, A., Cucchi, A., Savio, G., Giannico, C. Bianchi, M., 2008. Geological interpretation of PSInSAR data at regional scale. Sensors 8 (11), 7469-7492. http://dx.doi.org/10.3390/s8117469.

Nagler, T., Mayer, V., Rott, H., 2001. Feasibility of DInSAR for mapping complex motion fields of alpine ice- and rock- glaciers. In: Proceedings of the Third International Symposium on Retrieval of Bio- and Geophysical Parameters from SAR Data for Land Applications, 11-14 September 2001 (ESA SP-475, 2002). Sheffield, UK, pp. 377-382.

Notti, D., Davalillo, J.C., Herrera, G., Mora, O., 2010. Assessment of the performance of X-band satellite radar data for landslide mapping and monitoring: Upper Tena Valley case study. Nat. Hazards Earth Syst. Sci. 10, 1865-1875. http://dx. doi.org/10.5194/nhess-10-1865-2010.
Przyłucka, M., Herrera, G., Graniczny, M., Colombo, D., Béjar-Pizarro, M., 2015. Combination of conventional and advanced DInSAR to monitor very fast mining subsidence with TerraSAR-X data: Bytom City (Poland). Remote Sensing 7 (5), 5300-5328. http://dx.doi.org/10.3390/rs70505300.

Raucoules, D., Bourgine, B., Michele, M., Le Gozannet, G., Closset, L., Bremmer, C., Veldkamp, H., Tragheim, D., Bateson, L., Crosetto, M., Agudo, M., Engdahl, M., 2009. Validation and intercomparison of persistent scatterers interferometry: PSIC4 project results. J. Appl. Geophys. 68 (3), 335-347. http://dx.doi.org/ 10.1016/j.jappgeo.2009.02.003.

Rosen, P., Hensley, S., Joughin, I., Li, F., Madsen, S., Rodriguez, E., Goldstein, R., 2000. Synthetic aperture radar interferometry. Proc. IEEE 88 (3), 333-382. http://dx. doi.org/10.1109/5.838084.

Schmidt, D., Burgmann, R., 2003. Time-dependent land uplift and subsidence in the Santa Clara valley, California, from a large interferometric synthetic aperture radar data set. J. Geophys. Res. 108 (B9). http://dx.doi.org/10.1029/ 2002JB002267.

Singleton, A., Li, Z., Hoey, T., Muller, J.-P., 2014. Evaluating sub-pixel offset techniques as an alternative to D-InSAR for monitoring episodic landslide movements in vegetated terrain. Remote Sens. Environ. 147, 133-144. http:// dx.doi.org/10.1016/j.rse.2014.03.003.

Spreckels, V., Wegmüller, U., Strozzi, T., Musiedlak, J., Wichlacz, H.C., 2001. Detection and observation of underground coal mining-induced surface deformation with differential SAR interferometry. In: Proc. Joint Workshop of ISPRS Working Groups I/2, I/5 and IV/7 "High Resolution Mapping from Space", Hannover, Germany, 19-21 September 2001.

Strozzi, T., Kääb, A., Frauenfelder, R., 2004. Detecting and quantifying mountain permafrost creep from in situ inventory, space-borne radar interferometry and airborne digital photogrammetry. Int. J. Remote Sens. 25 (15), 2919-2931. http://dx.doi.org/10.1080/0143116042000192330.

Strozzi, T., Farina, P., Corsini, A., Ambrosi, C., Thüring, M., Zilger, J., Wiesmann, A., Wegmüller, U., Werner, C., 2005. Survey and monitoring of landslide displacements by means of L-band satellite SAR interferometry. Landslides 2 (3), 193-201. http://dx.doi.org/10.1007/s10346-005-0003-2.

Strozzi, T., Wegmuller, U., Keusen, H.R., Graf, K., Wiesmann, A., 2006. Analysis of the terrain displacement along a funicular by SAR interferometry. IEEE Geosci. Remote Sens. Lett. 3 (1), 15-18. http://dx.doi.org/10.1109/LGRS.2005.855072.

Strozzi, T Teatini, P. Tosi, L., 2009. TerraSAR-X reveals the impact of the mobile barrier works on Venice coastland stability. Remote Sens. Environ. 113, 2682 2688. http://dx.doi.org/10.1016/j.rse.2009.08.001.

Strozzi, T., Delaloye, R., Kääb, A., Ambrosi, C., Perruchoud, E., Wegmüller, U., 2010. Combined observations of rock mass movements using satellite SAR interferometry, differential GPS, airborne digital photogrammetry, and airborne photography interpretation. J. Geophys. Res. 115, 1-11. http://dx.doi. org/10.1029/2009JF001311.

Strozzi, T., Raetzo, H., Wegmüller, U., Papke, J., Caduff, R., Werner, C., Wiesmann, A. 2015. Satellite and terrestrial radar interferometry for the measurement of slope deformation. In: Lollino, G., Manconi, A., Guzzetti, F., Culshaw, M. Bobrowsky, P., Luino, F. (Eds.), Engineering Geology for Society and Territory, vol. 5. Springer International Publishing. http://dx.doi.org/10.1007/978-3-31909048-132.

Varnes, D.J., 1978. Slope movement types and processes. In: Schuster, R.L., Krizek, R. J. (Eds.), Landslides, Analysis and Control. Special Report 176: Transportation Research Board. National Academy of Sciences, Washington, DC, pp. 11-33.

Werner, C., Wegmuller, U., Strozzi, T., Wiesmann, A., 2003. Interferometric point target analysis for deformation mapping. In: Proc. IGARSS'03, vol. 7, Toulouse, France, 21-25 July 2003, pp. 4362-4364.

Wegmüller, U., Werner, C., Strozzi, T., Wiesmann, A., 2003. Multi-temporal interferometric point target analysis. In: Proc. Second International Workshop on the Analysis of Multitemporal Remote Sensing Images, Ispra, Italy, 16-18 July 2003.

Wegmuller, U., Werner, C., Strozzi, T. Wiesmann, A., 2004. Monitoring mining induced surface deformations. In: Proc. IGARSS'04, vol. 3, Anchorage, Alaska, USA, 20-24 September 2004, pp. 1933-1935.

Wirz, V., Geertsema, M., Gruber, S., Purves, R.S., 2015. Temporal Variability of Diverse Mountain Permafrost Slope Movements derived from Multi-year Daily GPS Data, Mattertal, Switzerland. Landslides. First online: 16 January 2015. http://dx.doi.org/10.1007/s10346-014-0544-3. 